\title{
Article \\ PLEK2, RRM2, GCSH: A Novel WWOX-Dependent Biomarker Triad of Glioblastoma at the Crossroads of Cytoskeleton Reorganization and Metabolism Alterations
}

\author{
Żaneta Kałuzińska *(1), Damian Kołat (1), Andrzej K. Bednarek (1) and Elżbieta Płuciennik (1) \\ Department of Molecular Carcinogenesis, Medical University of Lodz, 90-752 Lodz, Poland; \\ damian.kolat@stud.umed.lodz.pl (D.K.); andrzej.bednarek@umed.lodz.pl (A.K.B.); \\ elzbieta.pluciennik@umed.lodz.pl (E.P.) \\ * Correspondence: zaneta.kaluzinska@stud.umed.lodz.pl
}

check for updates

Citation: Kałuzińska, Ż.; Kołat, D.; Bednarek, A.K.; Płuciennik, E. PLEK2, RRM2, GCSH: A Novel

WWOX-Dependent Biomarker Triad of Glioblastoma at the Crossroads of Cytoskeleton Reorganization and Metabolism Alterations. Cancers 2021, 13, 2955. https://doi.org/10.3390/ cancers 13122955

Academic Editors: Karen E. Pollok and Axel H. Schönthal

Received: 19 March 2021

Accepted: 11 June 2021

Published: 12 June 2021

Publisher's Note: MDPI stays neutral with regard to jurisdictional claims in published maps and institutional affiliations.

Copyright: (c) 2021 by the authors Licensee MDPI, Basel, Switzerland. This article is an open access article distributed under the terms and conditions of the Creative Commons Attribution (CC BY) license (https:/ / creativecommons.org/licenses/by/ $4.0 /)$.
Simple Summary: Cytoskeleton reorganization affects the malignancy of glioblastoma. The WWOX gene is a tumor suppressor in glioblastoma and was found to modulate the cytoskeletal machinery in neural progenitor cells. To date, the role of this gene in the cytoskeleton or glioblastoma has been studied separately. Therefore, the purpose of this study was to investigate WWOX-dependent genes in glioblastoma and indicate cytoskeleton-related processes they are involved in. The most relevant WWOX-dependent genes were found to be PLEK2, RRM2, and GCSH, which have been proposed as novel biomarkers. Their biological functions suggest that there is an important link between cytoskeleton and metabolism, orchestrating tumor proliferation, metastasis, and resistance. Searching for such new therapeutic targets is important due to the constant lack of effective treatment for glioblastoma patients.

Abstract: Glioblastoma is one of the deadliest human cancers. Its malignancy depends on cytoskeleton reorganization, which is related to, e.g., epithelial-to-mesenchymal transition and metastasis. The malignant phenotype of glioblastoma is also affected by the WWOX gene, which is lost in nearly a quarter of gliomas. Although the role of WWOX in the cytoskeleton rearrangement has been found in neural progenitor cells, its function as a modulator of cytoskeleton in gliomas was not investigated. Therefore, this study aimed to investigate the role of WWOX and its collaborators in cytoskeleton dynamics of glioblastoma. Methodology on RNA-seq data integrated the use of databases, bioinformatics tools, web-based platforms, and machine learning algorithm, and the obtained results were validated through microarray data. PLEK2, RRM2, and GCSH were the most relevant $W W O X$-dependent genes that could serve as novel biomarkers. Other genes important in the context of cytoskeleton (BMP4, CCL11, CUX2, DUSP7, FAM92B, GRIN2B, HOXA1, HOXA10, KIF20A, NF2, SPOCK1, TTR, UHRF1, and WT1), metabolism (MTHFD2), or correlation with WWOX (COL3A1, $K I F 20 A, R N F 141$, and RXRG) were also discovered. For the first time, we propose that changes in WWOX expression dictate a myriad of alterations that affect both glioblastoma cytoskeleton and metabolism, rendering new therapeutic possibilities.

Keywords: GBM; glioblastoma; WWOX; PLEK2; RRM2; GCSH; biomarkers; cytoskeleton; metabolism

\section{Introduction}

Amongst gliomas, the most common aggressive primary brain tumor is glioblastoma IDH wild-type (GBM), constituting more than a half of the tumors originating from glia or glial precursors [1,2]. GBM may develop de novo (the primary tumor) or via malignant progression from lower-grade glioma (LGG) as glioblastoma IDH mutated [3] - regardless of derivation, patient's prognosis is dismal [4]. The malignant phenotype of GBM results from, e.g., dynamics of cytoskeleton $[5,6]$, which has been found to guide signaling pathways [7], proliferation [8], polarity [9], cell cycle [10], or epithelial-to-mesenchymal 
transition (EMT) [11] and metastasis [12]. Ultimately, cytoskeleton controls two processes that impact on cancer malignant behavior, i.e., cellular division and invasion [6]. Thus, it is not surprising that cytoskeleton and its components have often been considered in anti-cancer therapies or prognosis assessment [12-14], including in GBM [6,15,16].

One of the genes affecting both cytoskeleton and GBM is WW domain-containing oxidoreductase (WWOX), a haploinsufficient tumor suppressor described in many cancers, including GBM, for which it impairs malignant phenotype [17]. In the brain tissue, WWOX can be summarized as a global modulator of transcription and an important regulator of differentiation and maintenance [18]; this is complemented with the prognostic relevance of WWOX [19]. It is also an important modulator of metabolic pathways, regulating the synthesis of amino acids and lipids but also glycolysis or Krebs cycle. Its role in various metabolic disorders [20] or in cancer metabolism [21] was previously reported. Recently, our comprehensive review summarized the current knowledge about WWOX in the central nervous system (CNS), including brain tumors, i.e., astrocytoma, neuroblastoma, and glioblastoma [22]. For GBM, it has been found that WWOX downregulation may be a result of promoter hypermethylation or loss of heterozygosity $(\mathrm{LOH})$; the latter is related to tumor progression and contributes to $20 \%$ of gliomas [22]. Determining the role of WWOX in GBM is thought to be in the initial state [19]; hence, profound research is needed, especially in the cytoskeleton-related context, which remains enigmatic. Available data indicate that WW domain of WWOX collaborates, e.g., with dystroglycan, a transmembrane protein that interacts with utrophin and dystrophin, which also communicate with actin [23]. Such finding proves the implication of WWOX in complex machinery involving both extracellular matrix (ECM) and cytoskeleton [23]. Furthermore, it has been found that WWOX recognizes the PPXY motif of ezrin [24], a protein that links transmembrane signaling to the reorganization of cytoskeleton [25], influencing cell migration and tumor progression [24]. In the case of brain tissue, the ability of WWOX to bind and regulate glycogen synthase kinase $3 \beta$ (GSK-3 $\beta$ ) was proved to be important for Alzheimer's disease [26], in which a frequent WWOX downregulation is found among patients [27]. Lastly, WWOX silencing changed the expression profile of genes (e.g., DCLK, NEFL, NEFM, MAP2/4/6) involved in the cytoskeleton organization of neural progenitor cells [18].

It can be assumed that as a global modulator, WWOX will manifest its function directly or indirectly. Therefore, this research aims to examine the role of WWOX-dependent genes in terms of cytoskeleton reorganization in GBM. Simultaneously, the lethal nature of the de novo IDH wild-type glioblastoma does not leave too many solutions, and hence it is justified to investigate not only GBM but also low-grade tissue from which glioblastoma IDH mutated could arise afterwards.

\section{Results}

\subsection{WWOX Influenced a Number of Pathways and Biological Processes}

Optimal WWOX expression cut-point was determined to separate high- and lowexpressing groups of patients. The obtained cut-off value, 222.6, had significantly separated groups, showing better prognosis for patients with high WWOX expression level (Figure 1).

Performing gene set enrichment analysis (GSEA) with the use of the selected cut-point confirmed the presence of gene sets such as BIOCARTA/KEGG/REACTOME canonical pathways; chemical and genetic perturbations (CGP); gene ontology (GO): biological processes (BP) and molecular function (MF); cancer gene neighborhoods (CGN); and oncogenic and immunologic signatures, hallmarks, and positional gene sets. Collectively, 74 gene sets were taken into account, which was equivalent to 3046 core enrichment genes (Supplementary File S1). Ultimately, duplicate removal yielded 1898 genes.

\subsection{Global Distinction Indicated Both Clinical Features and Modules Worth Considering}

Together with their corresponding normal brain tissue, the GBM and LGG cohorts were distributed across Uniform Manifold Approximation and Projection (UMAP) dimensions using the 1898 genes from GSEA. Out of eight characteristics acquired from The 
Cancer Genome Atlas (TCGA) clinical data, half showed promising distribution. First, samples were divided on the basis of the tumor_type; normal brain samples were also included to allow simultaneous visualization with tumor samples using one variable (Figure 2A). Subsequently, samples were grouped according to neoplasm_histologic_grade (Figure 2B) and histological_type (Figure 2C), and finally age_at_initial_pathologic_diagnosis divided by median age (Figure 2D). The remaining clinical features (excluded from further analyses due to the lack of a clear pattern) are presented in Figure S1.
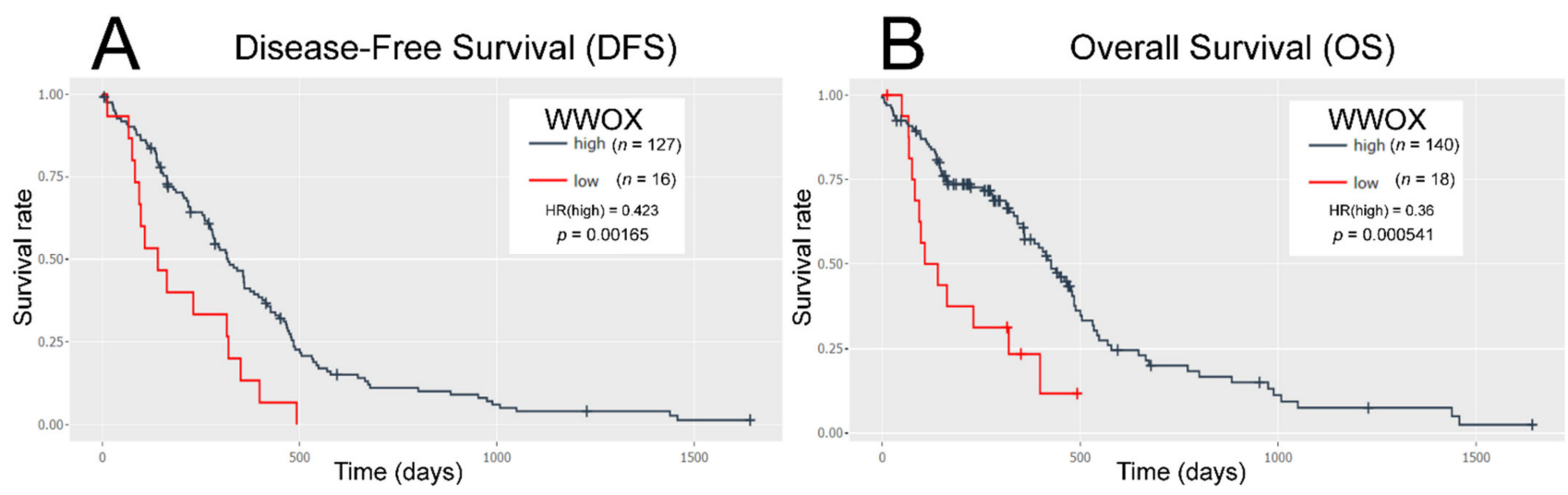

Figure 1. Survival analysis of low and high WWOX expression cut-off through Evaluate Cutpoints. (A) Disease-free survival (DFS). (B) Overall survival (OS).

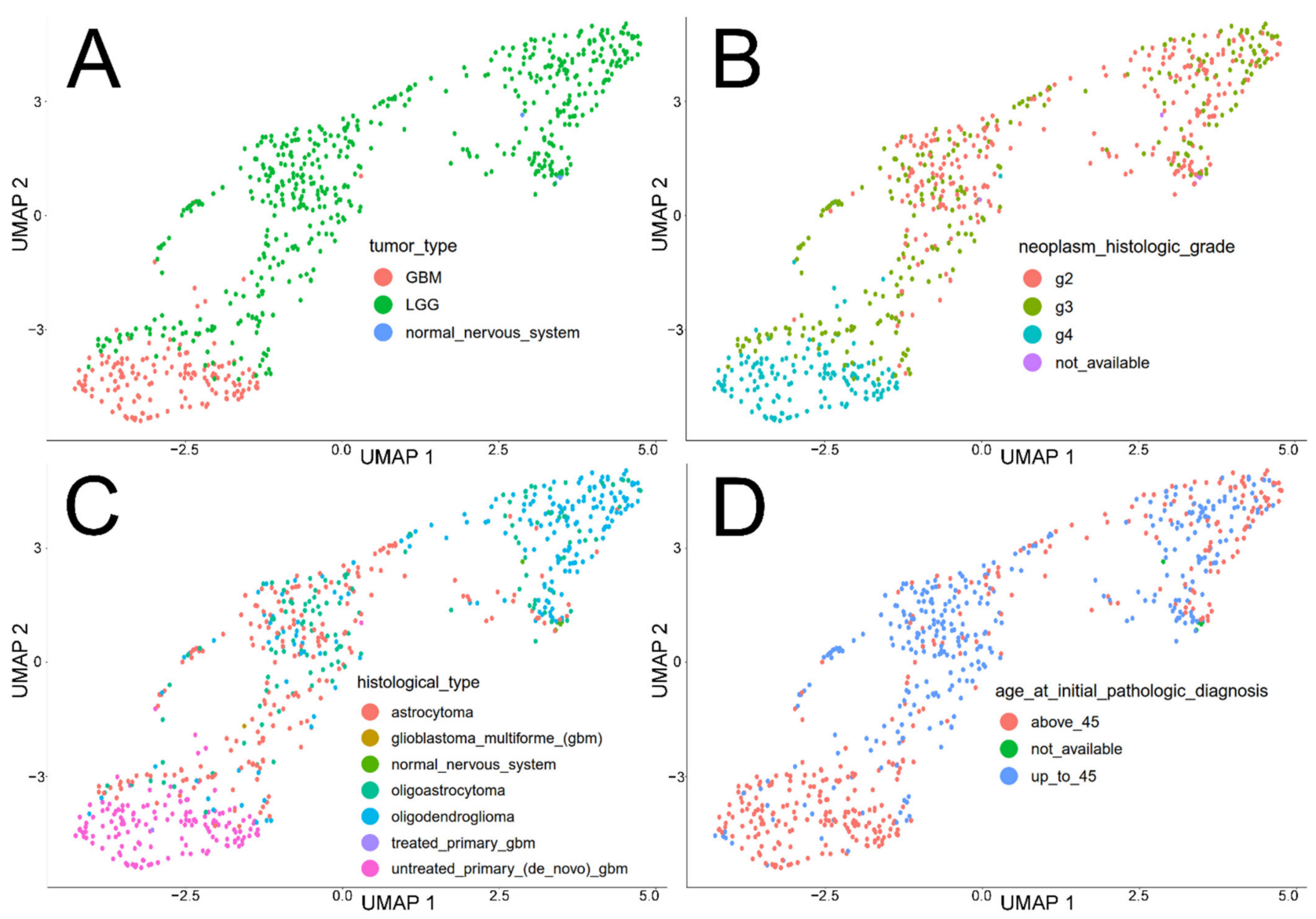

Figure 2. Global profiling of TCGA glioma samples with normal brain tissue through various clinical data. (A) tumor_type (specific cancers and corresponding normal tissue). (B) neoplasm_histologic_grade. (C) histological_type. (D) age_at_initial_ pathologic_diagnosis. 
The heatmaps were elaborated to split 1898 genes into modules and ease interpretation of specific comparison. The content of the modules is summarized in Supplementary File S2. Representative modules were selected on the basis of the contrasting pattern between the groups and the level of change in expression. For tumor_type (Figure 3A), the GBM was distinguished from normal brain (abbreviated NT) using modules 5 and 6. Module 1 was chosen to explain the differences between LGG and NT. GBM and LGG demonstrated different patterns for all modules; hence, two sets were adopted for independent examination - the first set comprised modules 2, 4, 5, and 7 combined together, while the second contained modules 1,3, and 6. For neoplasm_histologic_grade (Figure 3B), the G4 vs. G2 or G4 vs. G3 comparisons were explained using sets of modules $2+4+5$ +7 and $1+3+6$. Regarding histological_type (Figure 3C), we focused on the most drastic changes: the set of modules $1+5+7$ allowed astrocytoma (A) to be distinguished from both oligoastrocytoma (OA) and oligodendroglioma (OD). Additionally, using combined modules $1,4,5$, and 6 , the following comparisons were also included to identify treatmentrelated differences: (1) glioblastoma_multiforme combined with untreated_primary_gbm vs. normal_nervous_system; (2) glioblastoma_multiforme combined with untreated_primary_gbm vs. treated_primary_gbm; (3) treated_primary_gbm vs. normal_nervous_system. Lastly, for age_at_initial_pathologic_diagnosis, we indicated two sets of modules $(1+3$ and $2+4+5)$ that demonstrated opposite expression profile (Figure 3D). Henceforth, sets will be referred to as module numbers linked with " + ".
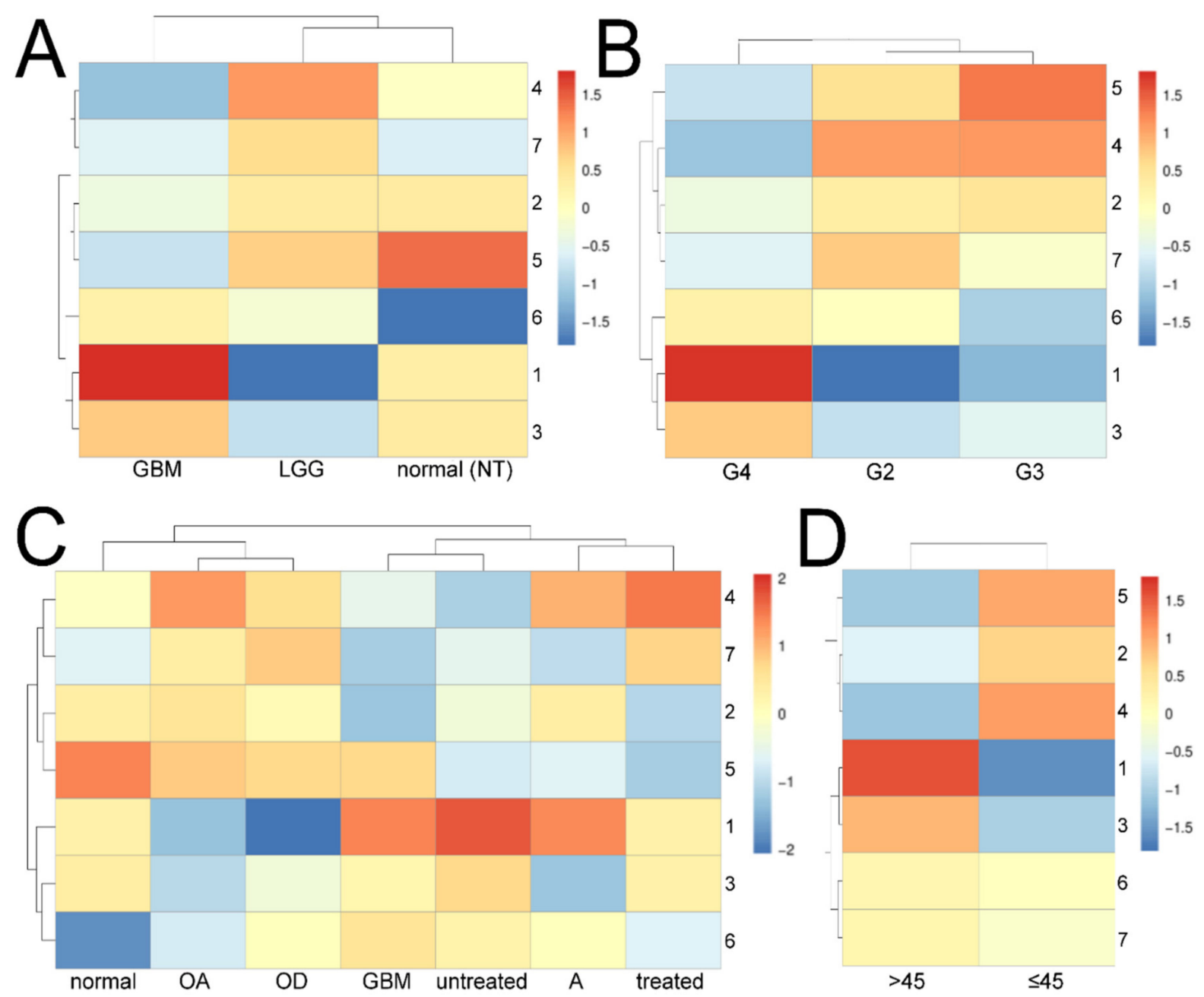

Figure 3. Heatmaps differentiating gliomas and normal brain tissue. (A) tumor_type (specific cancers and corresponding normal tissue). (B) neoplasm_histologic_grade. (C) histological_type. (D) age_at_initial_pathologic_diagnosis. 


\subsection{Differentially Expressed Genes Were Identified for Each Comparison}

Each comparison with corresponding set was summarized through volcano plot. The control in specific comparison was always the phenotype more resembling the natu$\mathrm{ral} /$ normal conditions, e.g., for high-grade vs. low-grade, the latter was used as a reference. A dedicated $\log _{2}$ fold-change $\left(\log _{2} \mathrm{FC}\right)$ was applied to specific analysis since the number of genes in a given comparison varied depending on the chosen modules. Using a different cut-off $\log _{2} \mathrm{FC}$ value, it was possible to indicate a small but strict group of genes presenting remarkable difference in expression. Differentially expressed genes (DEGs) were considered significant when at least $\log _{2} \mathrm{FC}=0.6$ (i.e., fold-change $\approx 1.5$ ) and $p<0.01$; however, in many comparisons, even $\log _{2} \mathrm{FC}=3.5$ was used to provide the most stringent group of DEGs.

For GBM vs. LGG comparison, 16 DEGs were identified through $1+3+6$ and 2 $+4+5+7$ sets; of these, 11 genes were upregulated and 5 were downregulated. The $5+6$ set of GBM vs. NT comparison indicated 7 DEGs with $\log _{2} \mathrm{FC}=1$ ( 3 up- and 4 downregulated), while module 1 of LGG vs. NT comparison determined 19 genes having $\log _{2} \mathrm{FC}>3.5$, with the vast majority being upregulated. The results for tumor_type are presented in Figure 4A. Secondly, three comparisons for neoplasm_histologic_grade (G4 vs. G2; G4 vs. G3; G3 vs. G2) were visualized through the $1+3+6$ and $2+4+5+7$ sets, resulting in six independent graphs. Altogether, more than 40 DEGs were selected, as summarized in Figure 4B. Subsequently, the $1+3$ set indicated four DEGs between groups of age_at_initial_pathologic_diagnosis (Figure 4C). Concerning histological types, astrocytoma differed from both oligoastrocytoma and oligodendroglioma in terms of only three genes of set $1+5+7$ with $\log _{2} \mathrm{FC}>2.5$. The remaining comparisons for this clinical feature revealed several dozen DEGs between the specific GBM phenotype vs. normal brain, and a few ones between treated (Tr.) or untreated (Untr.) high-grade gliomas based on the $1+4+5+$ 6 set (Figure 4D). 


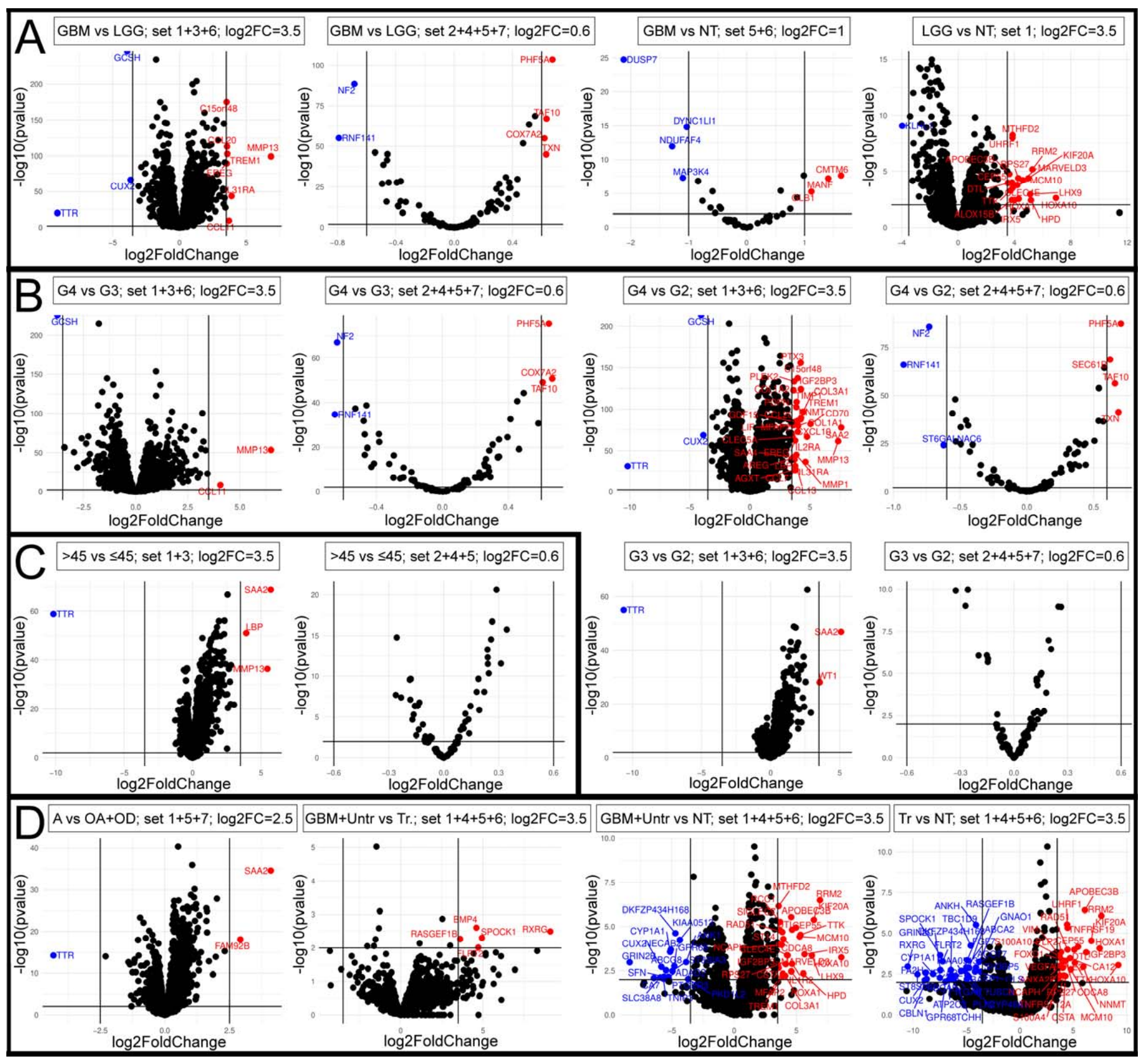

Figure 4. Differential gene expression analysis for each comparison. (A) Comparisons of tumor_type. (B) Comparisons of neoplasm_histologic_grade. (C) Comparisons of age_at_initial_pathologic_diagnosis. (D) Comparisons of histological_type. Genes marked with blue are downregulated while those in red are upregulated.

\section{The Most Relevant Genes Were Subjected to ROC Analysis}

Sequential elimination using Multiple Support Vector Machine Recursive Feature Elimination (mSVM-RFE) was performed to select the best three features (genes) per comparison. Due to small size of the groups, all comparisons for histological_type were based on the topTags() function. Ultimately, 14 out of 16 comparisons contained DEGs; these revealed 42 genes with supposed potential. However, some genes were identified in more than one comparison, resulting in a group of 30 genes. These were henceforth described as top genes. The most relevant genes, along with their ascending average rank (AvgRank) or with topTags() hierarchy, are listed in Table 1. 
Table 1. The most relevant DEGs of each comparison appraised by mSVM-RFE or topTags().

\begin{tabular}{|c|c|c|c|}
\hline Comparison & Set of Modules & Gene & AvgRank/Toptags \\
\hline \multirow{6}{*}{ GBM vs. LGG } & \multirow{3}{*}{$1+3+6$} & GCSH & 1.0 \\
\hline & & CUX2 & 2.2 \\
\hline & & C15orf48 & 3.6 \\
\hline & \multirow{3}{*}{$2+4+5+7$} & PHF5A & 1.0 \\
\hline & & NF2 & 2.0 \\
\hline & & TAF10 & 3.4 \\
\hline \multirow{3}{*}{ GBM vs. NT } & \multirow{3}{*}{$5+6$} & GLB1 & 1.0 \\
\hline & & CMTM6 & 2.3 \\
\hline & & DUSP7 & 3.6 \\
\hline \multirow{3}{*}{ LGG vs. NT } & \multirow{3}{*}{1} & MTHFD2 & 2.8 \\
\hline & & UHRF1 & 3.3 \\
\hline & & RPS27 & 4.7 \\
\hline \multirow{6}{*}{ G4 vs. G3 } & \multirow{3}{*}{$1+3+6$} & GCSH & 1.0 \\
\hline & & MMP13 & 2.0 \\
\hline & & CCL11 & 3.0 \\
\hline & \multirow{3}{*}{$2+4+5+7$} & PHF5A & 1.0 \\
\hline & & NF2 & 2.0 \\
\hline & & TAF10 & 3.3 \\
\hline \multirow{6}{*}{ G4 vs. G2 } & \multirow{3}{*}{$1+3+6$} & GCSH & 1.8 \\
\hline & & PLEK2 & 3.2 \\
\hline & & COL3A1 & 5.8 \\
\hline & \multirow{3}{*}{$2+4+5+7$} & PHF5A & 1.0 \\
\hline & & NF2 & 2.1 \\
\hline & & RNF141 & 2.9 \\
\hline \multirow{3}{*}{ G3 vs. G2 } & \multirow{3}{*}{$1+3+6$} & $S A A 2$ & 1.1 \\
\hline & & WT1 & 2.0 \\
\hline & & TTR & 2.9 \\
\hline \multirow{3}{*}{ A vs. $\mathrm{OA}+\mathrm{OD}$} & \multirow{3}{*}{$1+5+7$} & TTR & First (topTags) \\
\hline & & $S A A 2$ & Second (topTags) \\
\hline & & FAM92B & Third (topTags) \\
\hline \multirow{3}{*}{ Untr. GBM vs. Tr. } & \multirow{3}{*}{$1+4+5+6$} & $R X R G$ & First (topTags) \\
\hline & & BMP4 & Second (topTags) \\
\hline & & SPOCK1 & Third (topTags) \\
\hline \multirow{3}{*}{ Untr. GBM vs. NT } & \multirow{3}{*}{$1+4+5+6$} & HOXA10 & First (topTags) \\
\hline & & GRIN2B & Second (topTags) \\
\hline & & RRM2 & Third (topTags) \\
\hline \multirow{3}{*}{ Tr. GBM vs. NT } & \multirow{3}{*}{$1+4+5+6$} & RRM2 & First (topTags) \\
\hline & & HOXA1 & Second (topTags) \\
\hline & & KIF20A & Third (topTags) \\
\hline \multirow{3}{*}{$>45$ vs. $\leq 45$} & \multirow{3}{*}{$1+3$} & $S A A 2$ & 1.0 \\
\hline & & MMP13 & 2.1 \\
\hline & & $L B P$ & 3.0 \\
\hline
\end{tabular}

Elimination of insignificant or overfitted genes was possible via determination of area under the curve (AUC) in receiver operating characteristic (ROC) analysis. Some comparisons contained no valuable predictor, and data validation helped to decide whether to exclude them from subsequent step. The ROC analysis for all top genes is collected in Figure 5. The importance of top genes regarding glioma or cytoskeleton regulation is summarized in Table S1. 


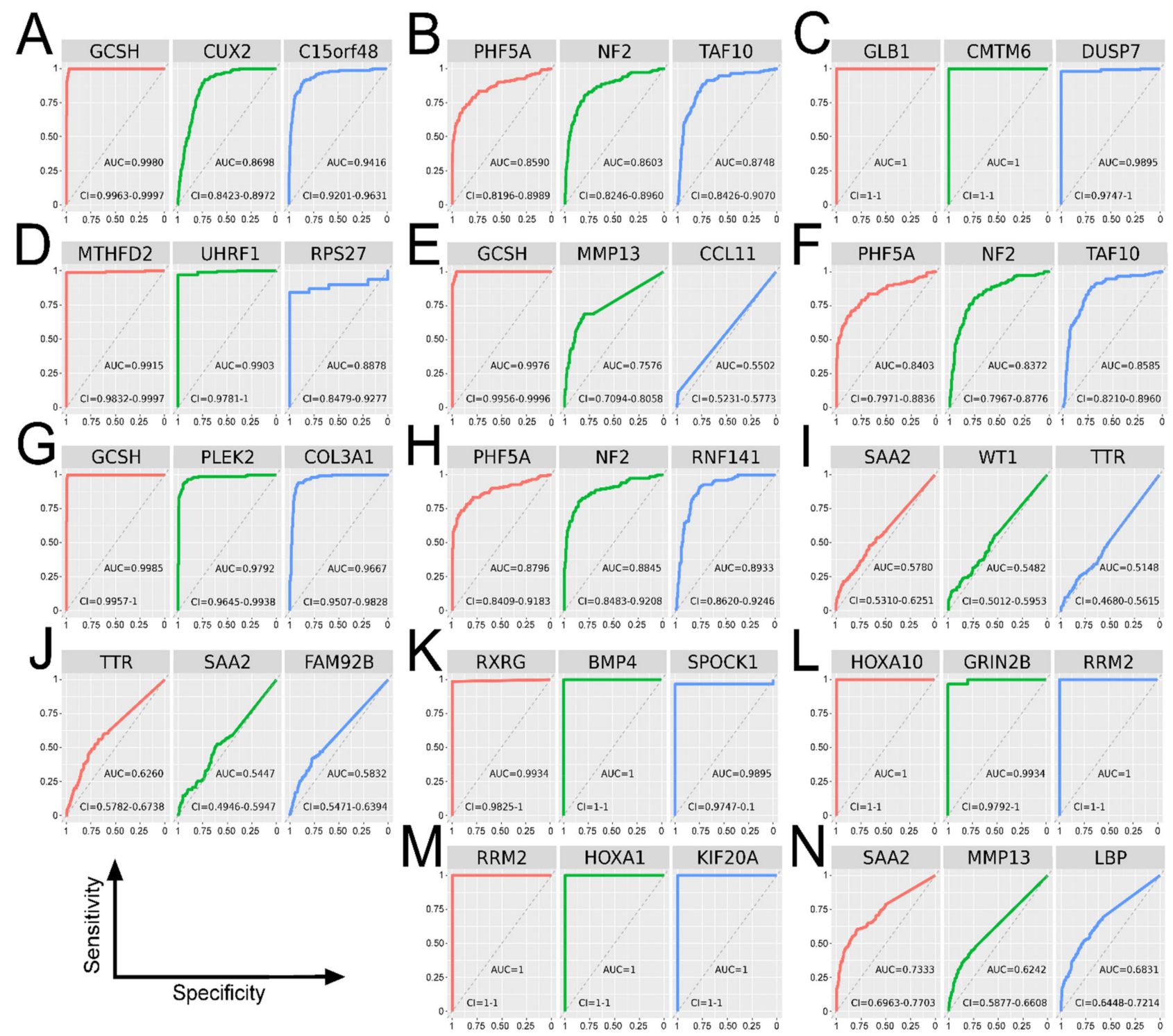

Figure 5. ROC analysis of top genes from comparisons-RNA-seq data. (A) GBM vs. LGG, set $1+3+6$. (B) GBM vs. LGG, set $2+4+5+7$. (C) GBM vs. NT, set $5+6$. (D) LGG vs. NT, set 1. (E) G4 vs. G3, set $1+3+6$. (F) G4 vs. G3, set $2+4+5+7$. (G) G4 vs. G2, set $1+3+6$. (H) G4 vs. G2, set $2+4+5+7$. (I) G3 vs. G2, set $1+3+6$. (J) A vs. OA and OD, set $1+5+7$. (K) Untr GBM vs. Tr, set $1+4+5+6$. (L) Untr GBM vs. NT, set $1+4+5+6$. (M) Tr vs. NT, set $1+4+5+6$. (N) $>45$ vs. $\leq 45$, set $1+3$.

\subsection{Validation Verified the Usefulness of Top Genes}

Independent microarray cohorts were used to certify RNA-seq findings; identical top genes were considered in specific clinical comparison (Figure 6).

This allowed us to exclude 3 out of 14 comparisons from further investigation; these comparisons were G3 vs. G2, set $1+3+6$; A vs. OA + OD, set $1+5+7$; untreated vs. treated GBM, set $1+4+5+6$. For the remaining comparisons, one gene with the highest mean AUC was selected. This yielded 9 genes from 11 significant comparisons, as the NF2 gene was appointed three times. These were C15orf48, CMTM6, GCSH, HOXA1, NF2, PLEK2, RRM2, SAA2, and UHRF1; together with their means of AUC, 95\% confidence interval (CI), and accuracy (ACC), they are presented in Table 2. 


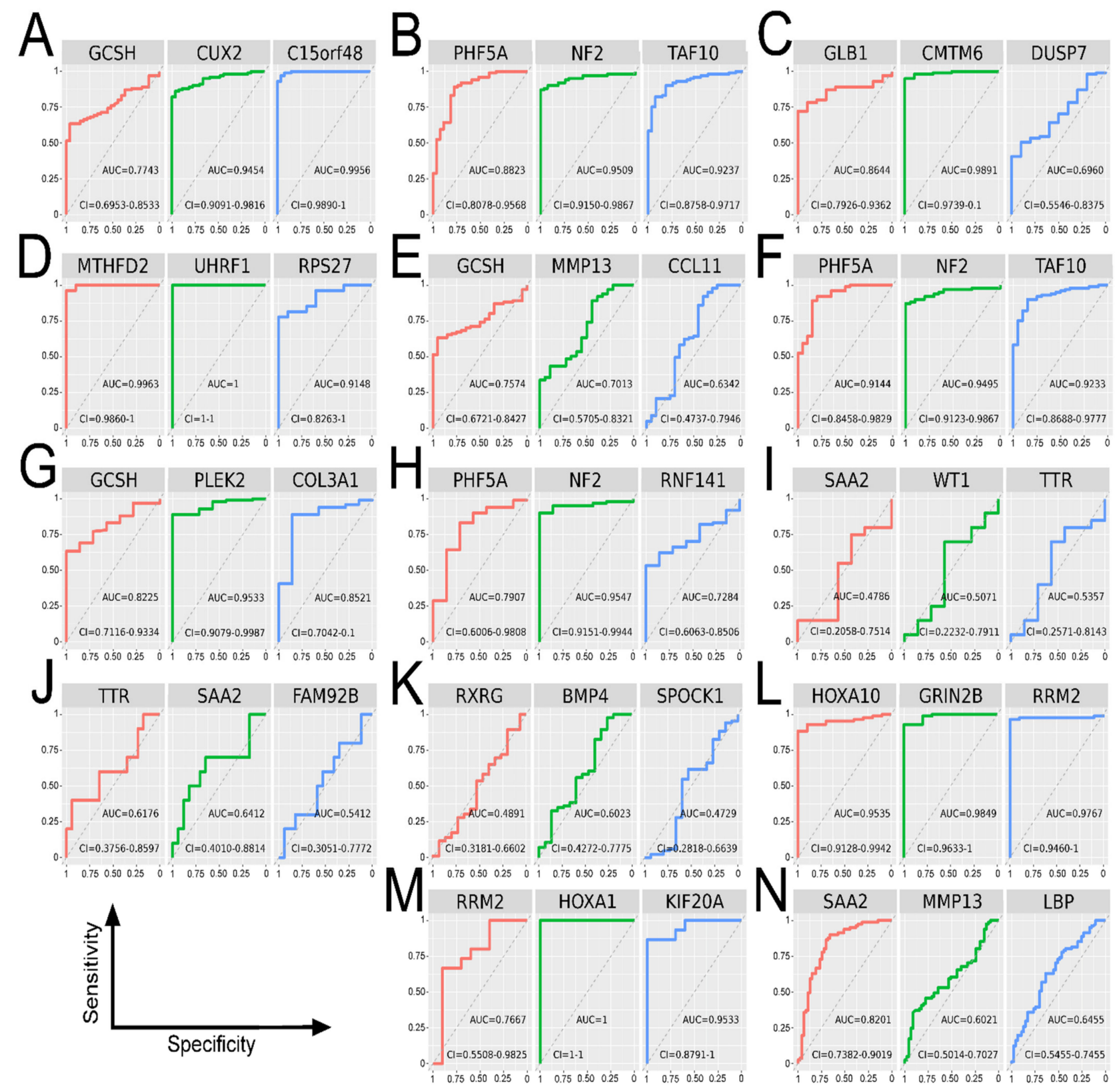

Figure 6. ROC analysis of top genes from comparisons-validation of the results using Agilent 244K G4502A microarray data. (A) GBM vs. LGG, set $1+3+6$. (B) GBM vs. LGG, set $2+4+5+7$. (C) GBM vs. NT, set $5+6$. (D) LGG vs. NT set 1 . (E) G4 vs. G3, set $1+3+6$. (F) G4 vs. G3, set $2+4+5+7$. (G) G4 vs. G2, set $1+3+6$. (H) G4 vs. G2, set $2+4+5+7$. (I) G3 vs. G2, set $1+3+6$. (J) A vs. OA and OD, set $1+5+7$. (K) Untr GBM vs. Tr, set $1+4+5+6$. (L) Untr GBM vs. NT, set $1+4$ $+5+6$. (M) Tr vs. NT, set $1+4+5+6$. $(\mathbf{N})>45$ vs. $\leq 45$, set $1+3$.

\subsection{Several Substantial Genes Were Correlated with WWOX and Possessed Prognostic Value}

Prior to focusing on the best nine explanatory genes, we correlated all top genes with WWOX to select subsidiary genes more related to WWOX but with slightly worse predictive properties. As forecasted, among all top genes (Table 3), and besides nine predictors, there were a few additional genes worth considering, e.g., COL3A1, KIF20A, RNF141, and RXRG. This resulted in a total of 13 genes that were then subjected to survival analysis, together with WWOX (Figure 7). Kaplan-Meier curves revealed that despite being at the forefront, UHRF1 was not found to be of prognostic importance and was excluded (Figure 7N). 
Table 2. Post-validation significant comparisons with the best explanatory gene.

\begin{tabular}{cccc}
\hline Comparison & Set of Modules & Gene & AUC/95\% CI/ACC \\
\hline GBM vs. LGG & $1+3+6$ & C15orf48 & $0.9686 / 0.9546-0.9816 / 0.9251$ \\
& $2+4+5+7$ & NF2 & $0.9056 / 0.8698-0.9414 / 0.8591$ \\
\hline GBM vs. NT & $5+6$ & CMTM6 & $0.9946 / 0.9870-1 / 0.9805$ \\
LGG vs. NT & 1 & UHRF1 & $0.9952 / 0.9891-1 / 0.9875$ \\
\hline \multirow{2}{*}{ G4 vs. G3 } & $1+3+6$ & GCSH & $0.8775 / 0.8339-0.9212 / 0.8255$ \\
& $2+4+5+7$ & NF2 & $0.8934 / 0.8545-0.9322 / 0.8402$ \\
\hline \multirow{2}{*}{ G4 vs. G2 } & $1+3+6$ & PLEK2 & $0.9663 / 0.9362-0.9963 / 0.9255$ \\
& $2+4+5+7$ & NF2 & $0.9196 / 0.8817-0.9576 / 0.8793$ \\
\hline Untr. GBM vs. NT & $1+4+5+6$ & RRM2 & $0.9884 / 0.9730-1 / 0.9861$ \\
Tr. GBM vs. NT & $1+4+5+6$ & $H O X A 1$ & $1 / 1-1 / 1$ \\
$>45$ vs. $\leq 45$ & $1+3$ & SAA2 & $0.7767 / 0.7173-0.8361 / 0.7551$
\end{tabular}

Table 3. Correlation analysis of the top genes with WWOX.

\begin{tabular}{cc}
\hline Gene & Correlation with WWOX \\
\hline BMP4 & $\mathrm{R}=0.28, p<0.0001$ \\
C15orf48 & $\mathrm{R}=-0.37, p<0.0001$ \\
CCL11 & $\mathrm{R}=-0.13, p<0.001$ \\
CMTM6 & $\mathrm{R}=-0.21, p<0.0001$ \\
COL3A1 & $\mathrm{R}=-0.51, p<0.0001$ \\
CUX2 & $\mathrm{R}=0.24, p<0.0001$ \\
DUSP7 & $\mathrm{R}=0.28, p<0.0001$ \\
FAM92B & $\mathrm{R}=-0.23, p<0.0001$ \\
GCSH & $\mathrm{R}=0.43, p<0.0001$ \\
GLB1 & $\mathrm{R}=-0.25, p<0.0001$ \\
GRIN2B & $\mathrm{R}=0.24, p<0.0001$ \\
HOXA1 & $\mathrm{R}=-0.26, p<0.0001$ \\
HOXA10 & $\mathrm{R}=-0.36, p<0.0001$ \\
KIF20A & $\mathrm{R}=-0.42, p<0.0001$ \\
LBP & $\mathrm{R}=-0.12, p<-0.0001$ \\
MMP13 & $\mathrm{R}=-0.34, p<0.0001$ \\
MTHFD2 & $\mathrm{R}=0.25, p<0.0001$ \\
NF2 & $\mathrm{R}=0.20, p<0.0001$ \\
PHF5A & $\mathrm{R}=-0.21, p<0.0001$ \\
PLEK2 & $\mathrm{R}=-0.44, p<0.0001$ \\
RNF141 & $\mathrm{R}=0.58, p<0.0001$ \\
RPS27 & $\mathrm{R}=-0.11, p<0.001$ \\
RRM2 & $\mathrm{R}=-0.42, p<0.0001$ \\
RXRG & $\mathrm{R}=0.45, p<0.0001$ \\
SAA2 & $\mathrm{R}=-0.30, p<0.0001$ \\
SPOCK1 & $\mathrm{R}=0.32, p<0.0001$ \\
TAF10 & $\mathrm{R}=-0.28, p<0.0001$ \\
THR & $\mathrm{R}=-0.033, p>0.05$ \\
WHF1 & $\mathrm{R}=0.078, p<0.05$ \\
& $\mathrm{R}=-0.13, p<0.001$ \\
\hline
\end{tabular}



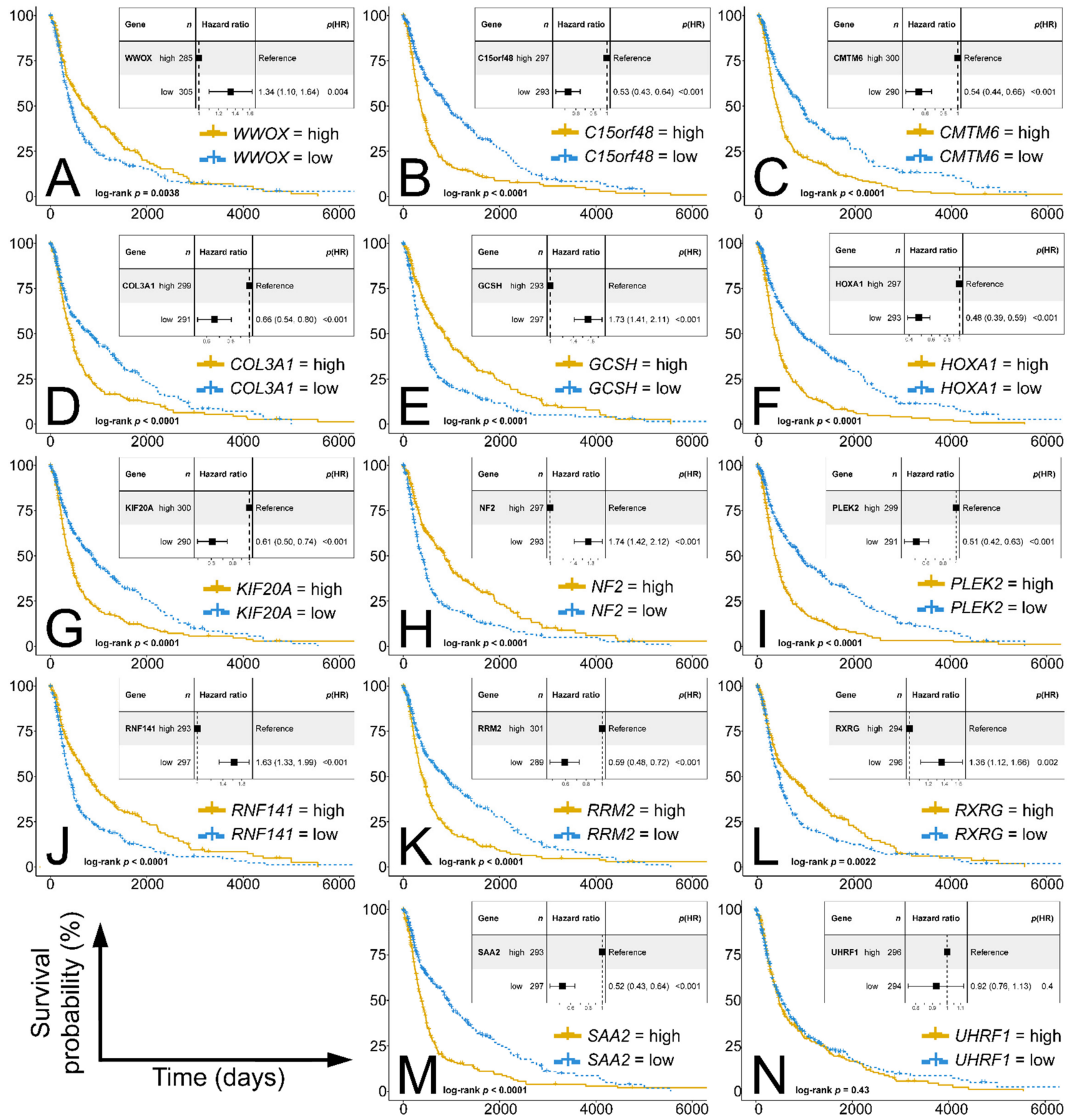

Figure 7. DFS analysis of the 13 most relevant genes and WWOX. (A) WWOX. (B) C15orf48. (C) CMTM6. (D) COL3A1. (E) GCSH. (F) HOXA1. (G) KIF20A. (H) NF2. (I) PLEK2. (J) RNF141. (K) RRM2. (L) RXRG. (M) SAA2. (N) UHRF1.

3.3. PLEK2, RRM2, and GCSH Were the Most Valuable in Differentiating Gliomas and Correlated with WWOX

The remaining 12 genes were visualized in terms of their expression across all RNA-seq samples. The selection of three the most relevant genes was based on their predictive value (AUC), effect on survival (DFS), correlation with WWOX, and transparency of expression difference across UMAP dimensions. These were found to be PLEK2, RRM2, and GCSH. Together with WWOX, their expression difference across UMAP is visualized in Figure 8; the same for the remaining genes can be found in Figure S2. 

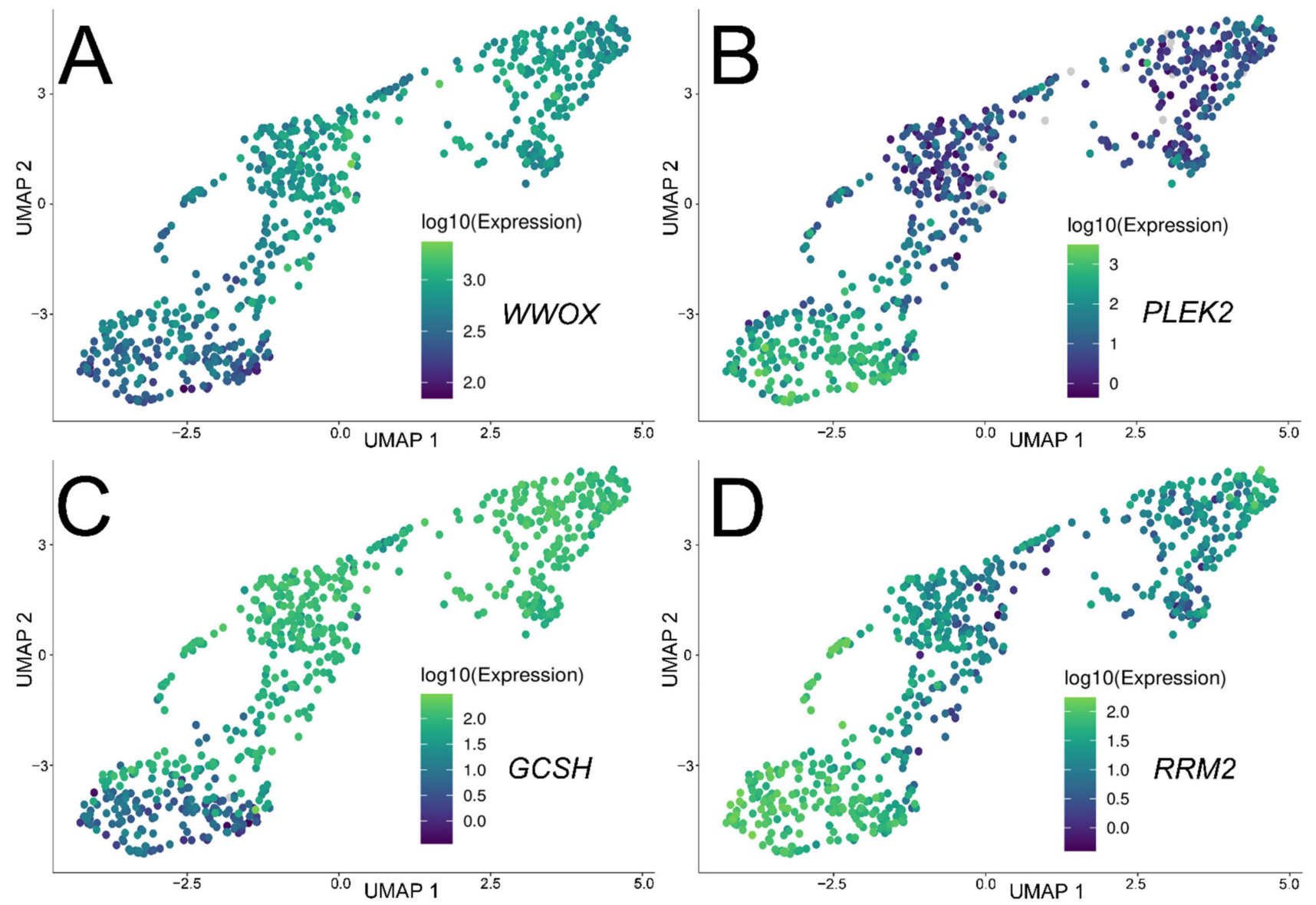

Figure 8. Spatial expression analysis of the 3 most relevant genes and WWOX. (A) WWOX. (B) PLEK2. (C) GCSH. (D) RRM2.

The GBM cohort demonstrated markedly increased PLEK2 and lowered GCSH expression compared to LGG, as well as a change in RRM2 expression similar to that of PLEK2. According to Gene Expression Profiling Interactive Analysis (GEPIA2), the last two are positively correlated, i.e., $\mathrm{R}=0.62, p<0.0001$ (Figure 9A); a negative correlation can be seen for PLEK2 and GCSH, i.e., $\mathrm{R}=-0.32, p<0.0001$ (Figure 9B). Lastly, GCSH and $R R M 2$ are not well correlated, indicated by a low correlation coefficient, i.e., $\mathrm{R}=-0.23$, $p<0.0001$ (Figure 9 C). Nevertheless, each of the three genes significantly correlated with WWOX (GCSH positively, PLEK2 and RRM2 negatively) as shown in Table 3. Finally, the prognostic signatures of PLEK2, RRM2, and GCSH were adjusted using survival curves with "Estimation of Stromal and Immune cells in Malignant Tumors using Expression data" (ESTIMATE) score as covariate (Figure 9D-F). 

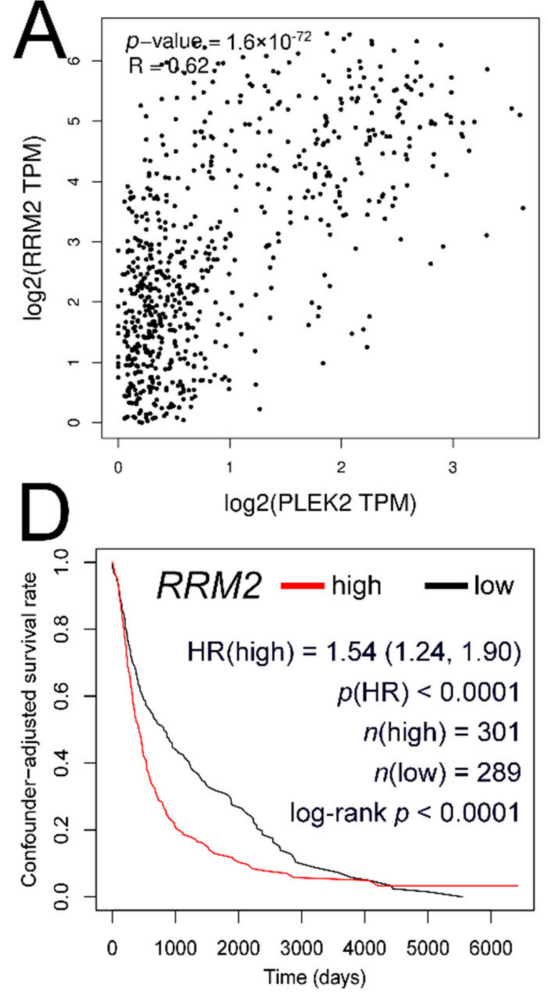
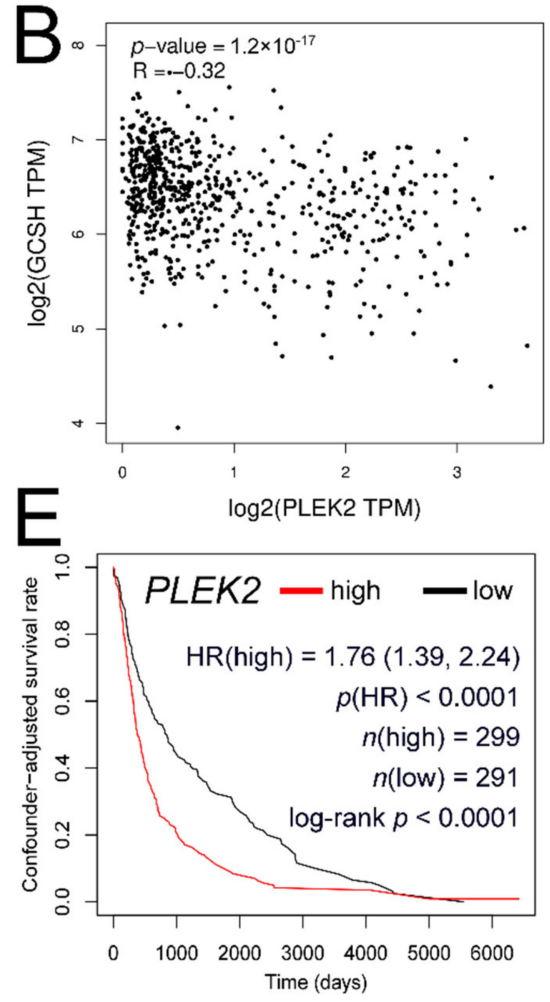
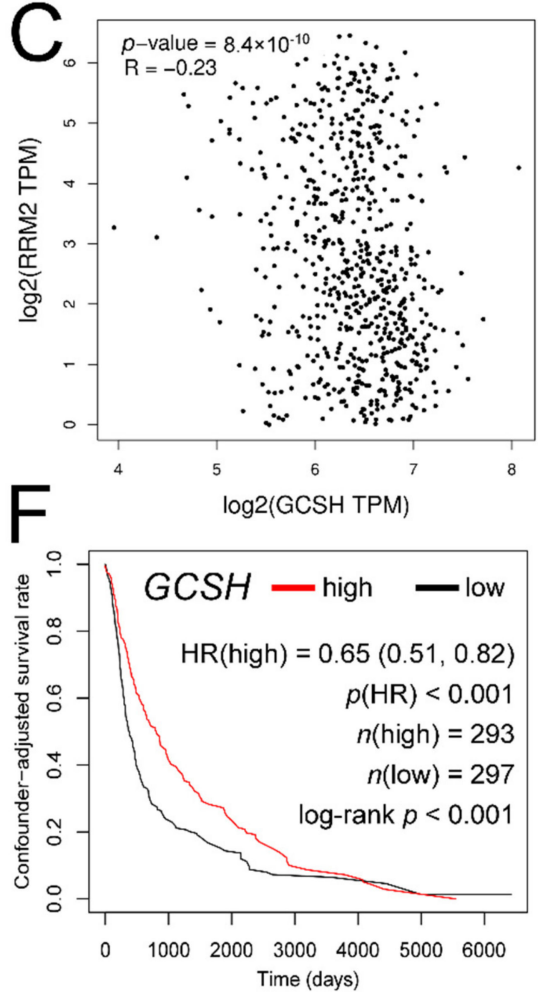

Figure 9. Correlation analysis of PLEK2, RRM2, and GCSH and its confounder-adjusted survival curves. (A) PLEK2 vs. RRM2. (B) PLEK2 vs. GCSH. (C) GCSH vs. RRM2. (D) ESTIMATE-adjusted survival for RRM2. (E) ESTIMATE-adjusted survival for PLEK2. (F) ESTIMATE-adjusted survival for GCSH.

\section{Discussion}

Glioblastoma is one of the deadliest human cancers [28]. Its malignant behavior results from, e.g., cytoskeleton reorganization that controls EMT and metastasis [11,29]. GBM is also affected by WWOX, a cytoskeleton-related protein that interacts with ezrin, dystroglycan, or GSK-3 $\beta$; it also influences on expression of DCLK, NEFL, NEFM, and $M A P 2 / 4 / 6$ genes. As a tumor suppressor, it is lost in nearly a quarter of gliomas through a LOH event $[22,23,26]$. This study is the first to evaluate the role of WWOX in cytoskeleton dynamics of glioblastoma. Low-grade glioma (from which IDH-mutated GBM could arise) was included in the analysis to determine whether WWOX loss might also switch expression profile at the earlier stages of carcinogenesis; this may potentially lead to an improved on-time diagnosis.

The main research milestones were (1) acquisition of a list of core enrichment genes using Evaluate Cutpoints and GSEA; (2) selection of the most important clinical features and comparisons using Monocle3; (3) establishment of the top genes and determining their role in the context of glioma and/or cytoskeleton; (4) validation of the results and selection of the three most relevant genes based on their predictive properties (AUC), impact on patients survival (DFS), correlation with WWOX, and transparency of spatial expression analysis across UMAP dimensions. Performing the edgeR $\rightarrow$ mSVM-RFE $\rightarrow$ ROC workflow independently for each clinical feature is justified, since the final verdict (indicating the most relevant gene) depended on the analyzed trait. Moreover, additional correlation analysis between the top genes and WWOX identified four important genes; likewise, multiple testing of the top genes allowed us to spot overfitted genes.

RNA-seq data showed that patients' prognosis worsens with a lower level of WWOX, which is consistent with previous findings in colon, bladder, breast [30], ovarian, prostate [22], gastric, cervical [31], and non-small cell lung [32] cancers. GSEA revealed that WWOX phenotype alters many pathways, e.g., signaling of tumor necrosis factor alpha (TNF- $\alpha$ ) 
via nuclear factor kappa B (NFkB), mammalian target of rapamycin complex 1 (mTORC1), phosphoinositide 3-kinase/protein kinase B/mTOR (PI3K/AKT/mTOR), protein 53 (p53), or Janus kinase 2 /signal transducer and activator of transcription (JAK/STAT). The other signatures also revealed hallmark, oncogenic, or computational gene sets; of these, many were found in the literature as WWOX-dependent processes (EMT [33], inflammatory response [34,35]) or pathways (TNF- $\alpha /$ NFkB [36], PI3K/AKT/mTOR [37], p53 [38], JAK/STAT [39]). The link between EMT and the cytoskeleton elements is necessary for mechanical strength and structural design involved in cancer migration and invasion [11,29]. Furthermore, the cytoskeleton was found to be crucial for inflammation-related processes, e.g., migration, cytokine production regulation, cell signaling, and adhesion [40]. Regarding pathways, TNF- $\alpha$ /NFkB [41], PI3K/AKT/mTOR [42], p53 [43], and JAK/STAT [44] have been implicated in cytoskeleton remodeling.

Our study revealed a noticeable subdivision of samples based on tumor type (or accompanied normal tissue), grading, histological type, or age. It was foreseeable that a higher grade of LGG (grade 3) or the presence of an astrocytoma histology are more indicative of GBM than lower grade or other types, as IDH mutated glioblastomas derive from astrocytomas [45]. However, it is not possible to make a complete distinction from oligodendroglioma as there are some glioblastomas with oligodendroglioma component (termed GBM-O) that might be pathologically defined as anaplastic oligoastrocytomas with necrosis $[46,47]$. The mean age has been also included as one of the patterns distinguishing glioblastomas [48], and the clinical practice confirms that application of surgical resection, radiotherapy, or chemotherapy is hampered in older age [49].

According to DEG investigation, we established the "top genes" term that contains 30 genes. More than half of them were found to be implicated in the regulation of cytoskeleton (i.e., BMP4, CCL11, CUX2, DUSP7, FAM92B, GRIN2B, HOXA1, HOXA10, KIF20A, MTHFD2, NF2, PLEK2, RRM2, SPOCK1, TTR, UHRF1, WT1), influencing actin, vimentin, ezrin, radixin, moesin, or tubulin. Most of the top genes were upregulated and/or contributed to promotion of GBM tumorigenicity, but few of them were downregulated and/or identified as protective prognostic factors, e.g., BMP4, DUSP7, GCSH, NF2, PHF5A, and RXRG.

At the post-validation stage, there were nine genes with at least acceptable discriminatory properties (AUC > 0.7) [50]. Most have previously been proposed as biomarkers in a specific tumor (or tumor-related condition): C15orf48 in esophageal cancer [51], NF2 in neurofibromatosis [52], CMTM6 in renal adenocarcinoma [53], PLEK2 in lung adenocarcinoma [54], RRM2 in glioma [55], HOXA1 in breast and gastric cancers [56], and SAA2 in renal cancer [57]. Interestingly, UHRF1 was indicated as a universal cancer biomarker [58], while GCSH seems to be newly observed. According to the modern algorithm developed by the Alliance of Genome Resources [59], the "automated description" indicates that GCSH is biomarker of amino acid metabolic disorder, which is a known abnormality in GBM $[60,61]$. Four additional genes were also included, as they presented high correlation with WWOX; these were COL3A1, KIF20A, RNF141, and RXRG. COL3A1, KIF20A, and $R X R G$ were described as valuable prognostic biomarkers in ovarian, renal cell, and breast carcinomas, respectively [62-64]. DFS analysis of selected 13 genes showed that GCSH, NF2, RNF141, and RXRG prolong survival while C15orf48, CMTM6, COL3A1, HOXA1, KIF20A, PLEK2, RRM2, and SAA2 shorten it.

The final stages of this study involved the selection of the best three genes-these were PLEK2, RRM2, and GCSH. They correlated with WWOX, and favorably (GCSH) or unfavorably (PLEK2 and RRM2) affected DFS. Across UMAP dimensions, GCSH was downregulated in GBM compared to LGG, but PLEK2 and RRM2 were upregulated. Finally, RRM2 and PLEK2 were correlated with each other, as were GCSH and PLEK2, but not RRM2 and GCSH; all three genes were also prognostic when ESTIMATE covariate was applied. Regarding phenotype comparisons for which these genes were representative, both GCSH and PLEK2 distinguished cancer grades: GCSH expression was lower in G4 than in G3, while PLEK2 was higher in G4 compared to G2. The changes in cytoskeleton were linked 
to increasing cancer grade, e.g., in colon cancer or glioblastoma. At first, Pachenari et al. reported that the proportion of actin and tubulin differs between low and high grade and that microtubules reorganize cytoskeleton to facilitate benign to malignant phenotype transition [65]. Secondly, Reiss-Zimmermann et al. found G4 glioblastoma to be softer than G3 astrocytoma [66]; this stems from cell stiffness, which is related to cytoskeleton reorganization [67]. On the other hand, RRM2 discriminated untreated GBM from normal nervous system; this is embedded in the TCGA clinical data of histological_type but it can also be considered as a typical comparison between glioblastoma and normal brain tissue. As previously mentioned, $R R M 2$ has been already proposed as an overexpressed biomarker with functional significance in glioma [55]. Hence, PLEK2 and GCSH should also be considered as prognostic biomarkers in GBM, since their spatial expression analysis was even clearer than that of literature-supported $R R M 2$.

To understand whether these three genes can undergo targeted therapy, it is necessary to analyze their biological function. In addition, GCSH expression is clearly lowered with increasing glioma grade, while that of PLEK2 and RRM2 is clearly elevated; therefore, GCSH does not fit the premise of targeted therapy, i.e., biological pathway inhibition [68]. Additionally, GCSH encodes one of four proteins responsible for glycine metabolism, which is only a single pathway of the whole complicated metabolic machinery [69]; its alteration should be considered in a broader perspective. Complexity is even greater as the cytoskeleton is implicated in carbohydrate metabolism [70], and conversely, actin and tubulin require energy from nucleotide hydrolysis to maintain structural dynamics [71]. Moreover, the other top gene, i.e., MTHFD2, was found to regulate metabolism through the folate cycle [72]. It was the best explanatory gene for the differences between LGG and normal brain tissue, suggesting that metabolic changes are not only restricted to glioblastoma.

$R R M 2$ encodes $\beta$ subunit of ribonucleotide reductase (RR), an enzyme acquiring $2^{\prime}$-deoxyribonucleotides from ribonucleotide $5^{\prime}$-diphosphates, which are crucial for the synthesis or repair of DNA [73]. It forms a dimer that may bind DNA [74]—each RRM2 monomer contains the tyrosyl radical and non-heme iron [73]. A sufficient supply of deoxyribonucleotides is required for uncontrolled DNA replication in cancer [75]; it is therefore not surprising that $R R M 2$ is often a target of molecular therapy [73,76,77]. Nowadays, there are several RRM2 inhibitors, i.e., radical scavengers, iron chelators, subunit polymerization inhibitors, or expression silencers [76,78-80]. A wide range of anti-RRM2 approaches focus on inhibition of proliferation, differentiation, and division but also invasion [75]. It has been found that $R R M 2$ knockdown inhibits cell proliferation via DNA damage-driven senescence induction [77].

Considering PLEK2, a protein with two pleckstrin homology $(\mathrm{PH})$ domains and one disheveled-Eg110-pleckstrin (DEP) domain [81] that is able to bind acidic phospholipids of cell membranes [82] or influence actin dynamics [83], targeted therapy is less developed yet already viable. Han et al. screened for small molecules potentially able to bind PLEK2 and identified compounds binding DEP domain; the lead compound, i.e., NUP-17d diminished proliferation similarly to ruxolitinib [82]. Despite moving to the cell membrane through its ability to bind phosphoinositides [84], it is also the effector of increased proliferation driven by JAK/STAT and PI3K/AKT signaling $[82,83]$. These two pathways were found in GSEA during discrimination of WWOX high/low groups. For JAK/STAT, Zhao et al. performed quantitative PCR preceded by chromatin immunoprecipitation (ChIP) to confirm the presence of STAT5 consensus-binding sites in PLEK2 promoter region [83]. Likewise, PLEK2 recruits phosphatidylinositol 3,4-bisphosphate and proteins, e.g., AKT, phosphoinositide-dependent kinase-1 (PDK1), PDK2, and mTOR, forming a complex that augments PI3K signaling [82]. Since PLEK2 induces cell spreading and guides tumor progression and metastasis [81], the development of new targeted therapy aimed at this oncogenic molecule is of utmost importance.

Finally, GCSH (or H-protein) is an integral core protein of glycine cleavage system (GCS), the major pathway of glycine degradation [85]. In short, GCS consists of a fourprotein complex that catalyzes glycine degradation into carbon dioxide, ammonia, and 
a methylene group that is accepted by tetrahydrofolate [86]. The functioning of GCS is reversible yet requires an intermediary state when the ternary complex is formed, i.e., compound of P-protein (or glycine decarboxylase; GLDC), the aminomethyl moiety of glycine, and H-protein [87]. This proves that in order to maintain glycine synthesis/degradation for subsequent processing, GCSH must be intact. Here, our study indicates that GCSH expression dramatically declines with increasing glioma grade. This is even more intriguing since cancer may benefit from GCS, as stated by Zhang et al. during lung adenocarcinoma research, wherein overexpression of GLDC increased tumor formation [88]. However, activity of GCS is mainly restricted to normal tissues of the brain, liver, and kidney [89], which suggests that context is tissue-dependent. Moreover, the brain is one of the few tissues with naturally high GLDC expression [90], suggesting the inverse tendency in typically non-GCS-expressing tissues that become cancerous and then overexpress GLDC. This can be supported by the findings of Zhuang et al. on hepatocellular carcinoma (HCC), wherein restoration of GCS proper activity (via GLDC overexpression due to its low level in malignant HCC) suppressed cancer progression via inhibition of both invasion and metastasis [91]. As mentioned above, the liver is (alongside the brain) one of few tissues maintaining the activity of GCS, and hence GLDC and other proteins of this complex. Therefore, this complex may be inhibited during carcinogenesis; this is in contrast to tissues with a naturally low or absent activity of GCS, where it would be increased. The main purpose of such a switch remains elusive, but to investigate this, glycine metabolism must be considered together with serine as they both are biosynthetically linked; they contribute to the one-carbon metabolism that cycles units of carbon from various amino acids [92]. Many discrepancies around glycine function have arisen, i.e., its uptake has been correlated with cancer proliferation [93], while excess glycine in the diet inhibited tumorigenesis in vivo [94,95]. This is supposedly due to the overall complexity of the metabolism but also insufficient understanding of glycine metabolism in carcinogenesis [96]. In theory, glycine is able to provide all precursors required to support nucleic acid synthesis [97], which is crucial for maintaining cancer cell growth [92]. Interestingly, serine is the main donor of one-carbon units [96] and a central hub of metabolic pathways in cancer [92], which might suggest its supremacy over glycine. Labuschagne et al. report that serine, rather than glycine, supports carbon metabolism and later proliferation [97]. The same authors highlighted that many tumors prefer serine consumption over glycine, and the latter does not substitute serine in nucleotide synthesis; what is more, the paradox of high glycine uptake during rapid proliferation can be a consequence rather than a cause of an such event [97]. This corresponds to our results, suggesting that GBM may preferably switch to serine consumption via GCSH downregulation. As GCSH was the gene that can distinguish G4 from G3 brain tumors, we speculate this occurs (beyond IDH wild-type GBM development) over the transformation from G3 astrocytoma to G4 glioblastoma. The only concern is how such deadly and incurable tumor handles with excess glycine, which if not metabolized may be converted to toxic by-products such as aminoacetone or methylglyoxal [86]. The explanation may again be serine-dependent; it has been found that not only excess glycine drives conversion to serine and inhibits glycine flux to purines but also high serine leads to glycine efflux [97]. Moreover, GBM is thought to be adapted to environmental conditions via serine-dependent redox homeostasis that enhances tumor survival [98]. Although glioblastoma metabolism remains poorly understood, it appears that antimetabolic therapy focused on serine pathway inhibition may be worth considering.

\section{Materials and Methods}

\subsection{Data Collection of Cancer Patients and Cut-Point Determination}

The entire methodology is summarized in Figure 10. Expression data of RNA-seq together with corresponding clinical annotation were collected from both GBM and LGG cohorts of TCGA-dedicated FireBrowse Repository (level 3 RNA-seqV2, RSEM normalized, data version of 28 January 2016 available at http: / / firebrowse.org/, accessed on 10 December 2020). Patients missing expression or clinical data were discarded from the study; no 
additional exclusion criteria were applied. The available data of paired normal brain tissues were additionally retrieved via the R-dedicated package TCGA-Assembler [99]. A total of 672 samples were included in the study. Determining the suitable WWOX expression cut-point to stratify the population into two groups was achieved with the help of the R-based Evaluate Cutpoints tool designed in our Department [100].

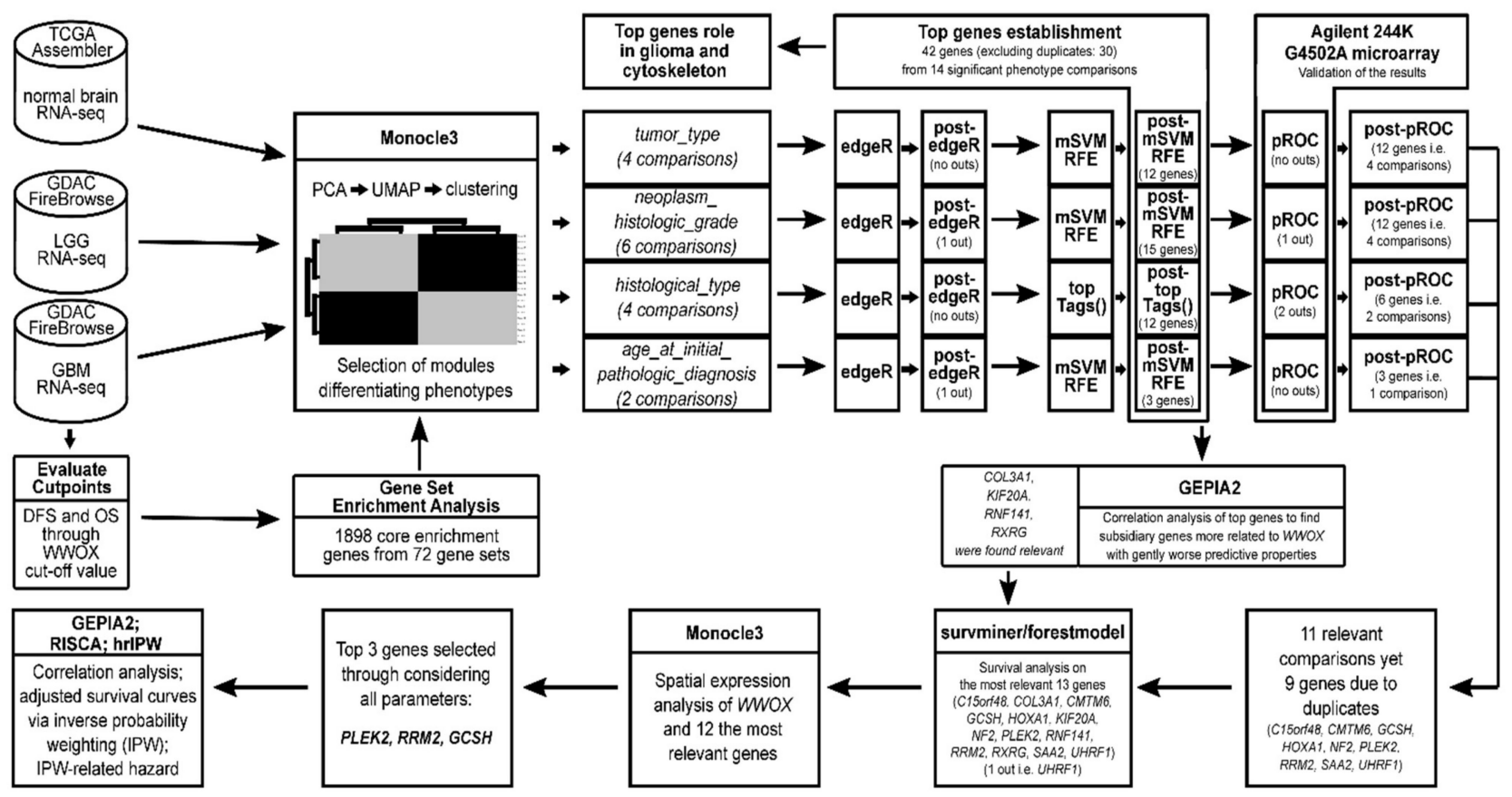

Figure 10. Methodology pipeline overview.

\subsection{Identification of Significant Differences between Phenotypes}

In order to determine which genes are WWOX-related in high-grade glioma, we conducted GSEA (https: / / www.gsea-msigdb.org/gsea, accessed on 20 December 2020) on eight major collections acquired from http:/ / software.broadinstitute.org/gsea/msigdb (accessed on 20 December 2020). Functional analysis was performed on 20,502 genes using the tTest metric with a weighted statistic to score hits/misses and permutation type concerning phenotype. From the whole and excluding duplicates, 1898 genes belonging to selected gene sets were chosen with a significance threshold of FDR $<0.25$.

\subsection{Global Profiling and Determination of Gene-Containing Modules}

Phenotype heterogeneity between GBM/LGG and normal brain tissue was investigated using the Monocle3 R package [101]. The dimensionality of the reduced space of 100 (num_dim) was chosen for the PCA pre-processing step (preprocess_cds()). Dimension reduction (reduce_dimension()) and individual clustering (cluster_cells()) within spaces were applied with the UMAP algorithm for dimensionality reduction method, upon which they were applied to base clustering (reduction_method). The clusters of individuals were compared with graph_test() function in accordance with Moran's I spatial autocorrelation analysis with $\mathrm{knn}$ neighbor graph and $0.05 \mathrm{q}$-value. Moreover, the genes varying across the clusters were grouped into modules through Louvain community analysis (find_gene_modules()) with parameters set to default. The modules were clustered on all of the individuals, enabling simultaneously comparison between tumors (e.g., GBM vs. LGG) and tumor vs. non-tumor samples (e.g., GBM/LGG vs. NT). The results were clustered with the Ward D2 method and visualized with pheatmap(). Expression differences for a given gene in the global projection were visualized using plot_cells(). The whole pipeline was per- 
formed according to the Monocle3 tutorial (https:/ / cole-trapnell-lab.github.io/monocle3/, accesssed on 26 December 2020).

\subsection{Examination of Differentially Expressed Genes}

Bioconductor's edgeR package allowed us to find DEGs using embedded DGEList() constructor and fitting a negative binomial generalized log-linear model to the read counts for each gene through $\operatorname{glmFit}()$ and glmLRT() with subsequent makeContrasts() between groups of specific comparison (default parameters). The most differentially expressed genes were extracted in the form of the table using topTags() ranked by absolute logFC with $p<0.01$ adjusted using Benjamini and Hochberg correction method. DEGs were visualized on volcano plots using ggrepel package and geom_text_repel() function.

\subsection{Relevant Features Investigation}

Multiple SVM-RFE approach by Duan et al. [102], which extended techniques of resampling compared to the original idea invented by Guyon et al. [103], was used to obtain top features (genes) across folds. Feature ranking was performed using svmRFE() function with $\mathrm{k}$-fold cross validation $(\mathrm{CV})$ of $\mathrm{k}=10$ to include a multiplicity of mSVM-RFE and halve.above $=100$. R-package $e 1071$ was included in the environment to allow SVM fitting. After setting up 10-fold CV, we performed feature ranking on all training sets and obtained top features across all folds using WriteFeatures() with a list of genes ordered by ascending AvgRank value (the lower number the better). The best genes (three per each significant comparison) were subjected to further investigation.

\subsection{Evaluation of Statistical Model Accuracy}

The ROC curves were evaluated on genes acquired from SVM machine learning algorithm. The pROC package was used for ROC analysis (estimating AUC, 95\% CI, ACC) and for plotting curve plot through ggroc using ggplot2 in R environment.

\subsection{Validation of the Results}

Validation of the findings on the basis of independent adequate cohorts was performed through Agilent 244K G4502A microarray normalized expression data acquired from the University of California Santa Cruz (UCSC) Xena repository. No LGG cohort exists on other platforms, e.g., AffyU133a (GBM microarray data alone was not sufficient to reflect comparisons).

\subsection{Correlation Analysis and Survival Curves}

GEPIA2 (http:/ / gepia2.cancer-pku.cn, accessed on 29 December 2020) was used to correlate the top genes with WWOX using Spearman's rank correlation coefficient. Analysis of genes' prognostic models on DFS endpoint in both GBM and LGG cohorts (merged together) was conducted using survminer and forestmodel R-packages. Survival curves were set on median group cut-off and forest plots were generated with Cox proportional hazards model. For the best three genes selected from the study, we developed the models with confounder-adjusted survival rate via inverse probability weighting (IPW) with the use of RISCA and hrIPW R-packages. The covariate was ESTIMATE combined score [104], which was divided into high and low groups on the basis of the median value. The logrank $p$-value was calculated using ipw.log.rank() function of RISCA, while hazard ratio estimation was acquired from hrIPW.

\section{Conclusions}

The change in WWOX gene expression dictates a myriad of alterations through WWOX-dependent genes that affect both glioblastoma cytoskeleton and metabolism. The greatest differences appear between glioblastoma and other gliomas (particularly in relation to tumor grade G4 vs. G3/G2), where GCSH and PLEK2 can be used to distinguish them since they exhibit opposite expression profiles in this regard. Together with the already 
described glioma biomarker, RRM2, we considered PLEK2 and GCSH as a novel WWOXdependent biomarker triad of glioblastoma, whose subsequent investigation is advisable. RRM2 and PLEK2 appear to be prognostic and therapeutic biomarkers; modulating their activity through targeted therapy might inhibit uncontrolled DNA replication or metastasis and proliferation, respectively (presumably driven by JAK/STAT and PI3K/AKT). Regarding GCSH, targeted therapy is not justified as its expression decreases with increasing glioma grade; hence, it is not a therapeutic biomarker. However, a broader view on onecarbon metabolism implied that more emphasis should be given to the serine pathway as a possible antimetabolic target. Nevertheless, the usefulness of PLEK2, RRM2, and GCSH as diagnostic or predictive biomarkers is yet to be confirmed. Other genes may also be worth investigating, including those playing a key role in the cytoskeleton (BMP4, CCL11, CUX2, DUSP7, FAM92B, GRIN2B, HOXA1, HOXA10, KIF20A, NF2, SPOCK1, TTR, UHRF1, and WT1), metabolism (MTHFD2), or correlation with WWOX (COL3A1, KIF20A, RNF141, and $R X R G)$.

Supplementary Materials: The following are available online at https://www.mdpi.com/article/ 10.3390/cancers13122955/s1, Figure S1: Residual global profiling of TCGA glioma samples accompanied by normal brain tissue through various clinical data, Figure S2: Spatial expression analysis of the remaining 9 most relevant genes, Table S1: Role of the top genes in glioma and cytoskeleton [105-160], Supplementary File S1: Gene sets acquired from enrichment analysis (Supplementary_File_S1.xlsx), Supplementary File S2: Content of modules from Monocle3 (Supplementary_File_S2.xlsx).

Author Contributions: Ż.K. and A.K.B. conceptualized the article. Ż.K., D.K. and A.K.B. established the methodology. Ż.K. and DK were responsible for software. A.K.B. and E.P. supervised the article. Ż.K. and D.K. visualized the results. Ż.K. wrote the original draft. Ż.K., D.K., and E.P. reviewed and edited the article. All authors read and approved the final manuscript.

Funding: This research was funded by Medical University of Lodz, grant number: 503/0-078-02/50301-001-19-00. The funding body had no role in study design, collection, analysis, data interpretation, or writing of the manuscript.

Institutional Review Board Statement: Not applicable.

Informed Consent Statement: Not applicable.

Data Availability Statement: Publicly available datasets were analyzed in this study. This data can be found here: https://gdac.broadinstitute.org/ and https:/ / xenabrowser.net/ (accessed on 10 December 2020).

Acknowledgments: The authors thank Magdalena Orzechowska for useful suggestions prior to manuscript preparation.

Conflicts of Interest: The authors have declared no competing interests.

\section{References}

1. Holland, E.C. Glioblastoma multiforme: The terminator. Proc. Natl. Acad. Sci. USA 2000, 97, 6242-6244. [CrossRef]

2. Ostrom, Q.T.; Gittleman, H.; Farah, P.; Ondracek, A.; Chen, Y.; Wolinsky, Y.; Stroup, N.C.; Kruchko, C.; Barnholtz-Sloan, J.S. CBTRUS statistical report: Primary brain and central nervous system tumors diagnosed in the United States in 2006-2010. Neuro. Oncol. 2013, 15 (Suppl. 2), ii1-ii56. [CrossRef]

3. Wiencke, J.K.; Zheng, S.; Jelluma, N.; Tihan, T.; Vandenberg, S.; Tamguney, T.; Baumber, R.; Parsons, R.; Lamborn, K.R.; Berger, M.S.; et al. Methylation of the PTEN promoter defines low-grade gliomas and secondary glioblastoma. Neuro Oncol. 2007, 9, 271-279. [CrossRef]

4. Lourenco, T.S.C.; Xavier-Magalhaes, A.; Pojo, M.M.B. Mechanisms of Aggressiveness in Glioblastoma: Prognostic and Potential Therapeutic Insights; IntechOpen: London, UK, 2013.

5. Dučić, T.; Paunesku, T.; Chen, S.; Ninković, M.; Speling, S.; Wilke, C.; Lai, B.; Woloschak, G. Structural and elemental changes in glioblastoma cells in situ: Complementary imaging with high resolution visible light- and X-ray microscopy. Analyst 2017, 142, 356-365. [CrossRef] [PubMed]

6. Cardelli, J.; Skalli, O. Divide and invade: The dynamic cytoskeleton of glioblastoma cells. Glioblastoma 2010, 167-183. [CrossRef]

7. Moujaber, O.; Stochaj, U. The cytoskeleton as regulator of cell signaling pathways. Trends Biochem. Sci. 2020, 45, 96-107. [CrossRef] [PubMed] 
8. Provenzano, P.P.; Keely, P.J. Mechanical signaling through the cytoskeleton regulates cell proliferation by coordinated focal adhesion and Rho GTPase signaling. J. Cell Sci. 2011, 124, 1195-1205. [CrossRef] [PubMed]

9. Lee, M.R.; Jeon, T.J. Cell migration: Regulation of cytoskeleton by Rap1 in Dictyostelium discoideum. J. Microbiol. 2012, 50, 555-561. [CrossRef]

10. Bendris, N.; Lemmers, B.; Blanchard, J.M. Cell cycle, cytoskeleton dynamics and beyond: The many functions of cyclins and CDK inhibitors. Cell Cycle 2015, 14, 1786-1798. [CrossRef] [PubMed]

11. Sun, B.O.; Fang, Y.; Li, Z.; Chen, Z.; Xiang, J. Role of cellular cytoskeleton in epithelial-mesenchymal transition process during cancer progression. Biomed. Rep. 2015, 3, 603-610. [CrossRef]

12. Fife, C.M.; McCarroll, J.A.; Kavallaris, M. Movers and shakers: Cell cytoskeleton in cancer metastasis. Br. J. Pharmacol. 2014, 171, 5507-5523. [CrossRef]

13. Stehn, J.R.; Haass, N.K.; Bonello, T.; Desouza, M.; Kottyan, G.; Treutlein, H.; Zeng, J.; Nascimento, P.B.B.; Sequeira, V.B.; Butler, T.L.; et al. A novel class of anticancer compounds targets the actin cytoskeleton in tumor cells. Cancer Res. 2013, 73, 5169-5182. [CrossRef]

14. Schiewek, J.; Schumacher, U.; Lange, T.; Joosse, S.A.; Wikman, H.; Pantel, K.; Mikhaylova, M.; Kneussel, M.; Linder, S.; Schmalfeldt, B.; et al. Clinical relevance of cytoskeleton associated proteins for ovarian cancer. J. Cancer Res. Clin. Oncol. 2018, 144, 2195-2205. [CrossRef]

15. Kiang, K.M.; Zhang, P.; Li, N.; Zhu, Z.; Jin, L.; Leung, G.K. Loss of cytoskeleton protein ADD3 promotes tumor growth and angiogenesis in glioblastoma multiforme. Cancer Lett. 2020, 474, 118-126. [CrossRef] [PubMed]

16. Masoumi, S.; Harisankar, A.; Gracias, A.; Bachinger, F.; Fufa, T.; Chandrasekar, G.; Gaunitz, F.; Walfridsson, J.; Kitambi, S.S. Understanding cytoskeleton regulators in glioblastoma multiforme for therapy design. Drug Des. Devel. Ther. 2016, 10, $2881-2897$. [PubMed]

17. Kosla, K.; Nowakowska, M.; Pospiech, K.; Bednarek, A.K. WWOX modulates the gene expression profile in the T98G glioblastoma cell line rendering its phenotype less malignant. Oncol. Rep. 2014, 32, 1362-1368. [CrossRef]

18. Kosla, K.; Pluciennik, E.; Styczen-Binkowska, E.; Nowakowska, M.; Orzechowska, M.; Bednarek, A.K. The WWOX gene influences cellular pathways in the neuronal differentiation of human neural progenitor cells. Front. Cell Neurosci. 2019, 13, 391. [CrossRef] [PubMed]

19. Liu, S.Y.; Chiang, M.F.; Chen, Y.J. Role of WW domain proteins WWOX in development, prognosis, and treatment response of glioma. Exp. Biol Med. 2015, 240, 315-323. [CrossRef]

20. Tanna, M.; Aqeilan, R.I. Modeling WWOX loss of function in vivo: What have we learned? Front. Oncol. 2018, 8, 420. [CrossRef]

21. Abu-Remaileh, M.; Aqeilan, R.I. Tumor suppressor WWOX regulates glucose metabolism via HIF1alpha modulation. Cell Death Differ. 2014, 21, 1805-1814. [CrossRef]

22. Kosla, K.; Kaluzinska, Z.; Bednarek, A.K. The WWOX gene in brain development and pathology. Exp. Biol. Med. 2020, 245, 1122-1129. [CrossRef]

23. Ilsley, J.L.; Sudol, M.; Winder, S.J. The WW domain: Linking cell signalling to the membrane cytoskeleton. Cell Signal. 2002, 14, 183-189. [CrossRef]

24. Salah, Z.; Aqeilan, R.; Huebner, K. WWOX gene and gene product: Tumor suppression through specific protein interactions. Future Oncol. 2010, 6, 249-259. [CrossRef]

25. Gourley, C.; Paige, A.J.; Taylor, K.J.; Ward, C.; Kuske, B.; Zhang, J.; Sun, M.; Janczar, S.; Harrison, D.J.; Muir, M.; et al. WWOX gene expression abolishes ovarian cancer tumorigenicity in vivo and decreases attachment to fibronectin via integrin alpha3. Cancer Res. 2009, 69, 4835-4842. [CrossRef] [PubMed]

26. Chang, H.T.; Liu, C.C.; Chen, S.T.; Yap, Y.V.; Chang, N.S.; Sze, C.I. WW domain-containing oxidoreductase in neuronal injury and neurological diseases. Oncotarget 2014, 5, 11792-11799. [CrossRef]

27. Liu, C.C.; Ho, P.C.; Lee, I.T.; Chen, Y.A.; Chu, C.H.; Teng, C.C.; Wu, S.N.; Sze, C.I.; Chiang, M.F.; Chang, N.S. WWOX phosphorylation, signaling, and role in neurodegeneration. Front. Neurosci. 2018, 12, 563. [CrossRef]

28. Gimple, R.C.; Bhargava, S.; Dixit, D.; Rich, J.N. Glioblastoma stem cells: Lessons from the tumor hierarchy in a lethal cancer. Genes Dev. 2019, 33, 591-609. [CrossRef] [PubMed]

29. Yilmaz, M.; Christofori, G. EMT, the cytoskeleton, and cancer cell invasion. Cancer Metastasis Rev. 2009, 28, 15-33. [CrossRef]

30. O'Keefe, L.V.; Lee, C.S.; Choo, A.; Richards, R.I. Tumor suppressor WWOX contributes to the elimination of tumorigenic cells in drosophila melanogaster. PLoS ONE 2015, 10, e0136356. [CrossRef] [PubMed]

31. Pluciennik, E.; Nowakowska, M.; Galdyszynska, M.; Popeda, M.; Bednarek, A.K. The influence of the WWOX gene on the regulation of biological processes during endometrial carcinogenesis. Int. J. Mol. Med. 2016, 37, 807-815. [CrossRef]

32. Aldaz, C.M.; Ferguson, B.W.; Abba, M.C. WWOX at the crossroads of cancer, metabolic syndrome related traits and CNS pathologies. Biochim. Biophys. Acta 2014, 1846, 188-200. [CrossRef]

33. Pluciennik, E.; Nowakowska, M.; Pospiech, K.; Stepien, A.; Wolkowicz, M.; Galdyszynska, M.; Popeda, M.; Wojcik-Krowiranda, K.; Bienkiewicz, A.; Bednarek, A.K. The role of WWOX tumor suppressor gene in the regulation of EMT process via regulation of CDH1-ZEB1-VIM expression in endometrial cancer. Int. J. Oncol. 2015, 46, 2639-2648. [CrossRef]

34. Singla, S.; Chen, J.; Sethuraman, S.; Sysol, J.R.; Gampa, A.; Zhao, S.; Machado, R.F. Loss of lung WWOX expression causes neutrophilic inflammation. Am. J. Physiol. Lung Cell Mol. Physiol. 2017, 312, L903-L911. [CrossRef] 
35. Wang, W.J.; Ho, P.C.; Nagarajan, G.; Chen, Y.A.; Kuo, H.L.; Subhan, D.; Su, W.P.; Chang, J.Y.; Lu, C.Y.; Chang, K.T.; et al. WWOX possesses N-terminal cell surface-exposed epitopes WWOX7-21 and WWOX7-11 for signaling cancer growth suppression and prevention in vivo. Cancers 2019, 11, 1818. [CrossRef] [PubMed]

36. Chen, S.J.; Huang, S.S.; Chang, N.S. Role of WWOX and NF-kappaB in lung cancer progression. Transl. Respir. Med. $2013,1,15$. [CrossRef] [PubMed]

37. Qin, L.; Li, X.; Lin, Z.; Li, H.; Mo, Y.; Su, F.; Mo, W.; Yang, Z. EBV-LMP1 regulating AKT/mTOR signaling pathway and WWOX in nasopharyngeal carcinoma. Int. J. Clin. Exp. Pathol. 2017, 10, 8619-8625. [PubMed]

38. Abdeen, S.K.; Aqeilan, R.I. Decoding the link between WWOX and p53 in aggressive breast cancer. Cell Cycle 2019, 18, 1177-1186. [CrossRef] [PubMed]

39. Chang, R.; Song, L.; Xu, Y.; Wu, Y.; Dai, C.; Wang, X.; Sun, X.; Hou, Y.; Li, W.; Zhan, X.; et al. Loss of Wwox drives metastasis in triple-negative breast cancer by JAK2/STAT3 axis. Nat. Commun. 2018, 9, 3486. [CrossRef] [PubMed]

40. Kopecki, Z.; Ludwig, R.J.; Cowin, A.J. Cytoskeletal regulation of inflammation and its impact on skin blistering disease epidermolysis bullosa acquisita. Int. J. Mol. Sci. 2016, 17, 1116. [CrossRef]

41. Jackman, R.W.; Rhoads, M.G.; Cornwell, E.; Kandarian, S.C. Microtubule-mediated NF-kappaB activation in the TNF-alpha signaling pathway. Exp. Cell Res. 2009, 315, 3242-3249. [CrossRef]

42. Fan, Z.; Li, C.; Qin, C.; Xie, L.; Wang, X.; Gao, Z.; Qiangbacuozhen; Wang, T.; Yu, L.; Liu, H. Role of the PI3K/AKT pathway in modulating cytoskeleton rearrangements and phenotype switching in rat pulmonary arterial vascular smooth muscle cells. $D N A$ Cell Biol. 2014, 33, 12-19. [CrossRef]

43. Ebata, T.; Hirata, H.; Kawauchi, K. Functions of the tumor suppressors p53 and Rb in actin cytoskeleton remodeling. Biomed. Res. Int. 2016, 2016, 9231057. [CrossRef]

44. Gao, H.; Priebe, W.; Glod, J.; Banerjee, D. Activation of signal transducers and activators of transcription 3 and focal adhesion kinase by stromal cell-derived factor 1 is required for migration of human mesenchymal stem cells in response to tumor cell-conditioned medium. Stem. Cells 2009, 27, 857-865. [CrossRef]

45. Arcella, A.; Limanaqi, F.; Ferese, R.; Biagioni, F.; Oliva, M.A.; Storto, M.; Fanelli, M.; Gambardella, S.; Fornai, F. Dissecting molecular features of gliomas: Genetic loci and validated biomarkers. Int. J. Mol. Sci. 2020, 21, 685. [CrossRef]

46. Wang, Y.; Li, S.; Chen, L.; You, G.; Bao, Z.; Yan, W.; Shi, Z.; Chen, Y.; Yao, K.; Zhang, W.; et al. Glioblastoma with an oligodendroglioma component: Distinct clinical behavior, genetic alterations, and outcome. Neuro. Oncol. 2012, 14, 518-525. [CrossRef] [PubMed]

47. Hartmann, C.; von Deimling, A. Molecular pathology of oligodendroglial tumors. Recent Results Cancer Res. 2009, 171, 25-49. [PubMed]

48. Ohgaki, H.; Kleihues, P. Genetic pathways to primary and secondary glioblastoma. Am. J. Pathol. 2007, 170, 1445-1453. [CrossRef] [PubMed]

49. Lin, Z.; Yang, R.; Li, K.; Yi, G.; Li, Z.; Guo, J.; Zhang, Z.; Junxiang, P.; Liu, Y.; Qi, S.; et al. Establishment of age group classification for risk stratification in glioma patients. BMC Neurol. 2020, 20, 310. [CrossRef] [PubMed]

50. Mandrekar, J.N. Receiver operating characteristic curve in diagnostic test assessment. J. Thorac. Oncol. 2010, 5, 1315-1316. [CrossRef]

51. Uemura, N.; Kondo, T. Current status of predictive biomarkers for neoadjuvant therapy in esophageal cancer. World J. Gastrointest Pathophysiol. 2014, 5, 322-334. [CrossRef] [PubMed]

52. Hanemann, C.O.; Blakeley, J.O.; Nunes, F.P.; Robertson, K.; Stemmer-Rachamimov, A.; Mautner, V.; Kurtz, A.; Ferguson, M.; Widemann, B.C.; Evans, D.G.; et al. Current status and recommendations for biomarkers and biobanking in neurofibromatosis. Neurology 2016, 87, S40-S48. [CrossRef]

53. Tulchiner, G.; Brunner, A.; Schmidinger, M.; Staudacher, N.; Orme, J.J.; Thurnher, M.; Horninger, W.; Culig, Z.; Pichler, R. CMTM6 expression as a potential biomarker for immunotherapy in metastatic renal cell carcinoma. BJU Int. 2021. [CrossRef]

54. Zhang, W.; Li, T.; Hu, B.; Li, H. PLEK2 gene upregulation might independently predict shorter progression-free survival in lung adenocarcinoma. Technol. Cancer Res. Treat. 2020, 19, 1533033820957030. [CrossRef]

55. Sun, H.; Yang, B.; Zhang, H.; Song, J.; Zhang, Y.; Xing, J.; Yang, Z.; Wei, C.; Xu, T.; Yu, Z.; et al. RRM2 is a potential prognostic biomarker with functional significance in glioma. Int. J. Biol. Sci. 2019, 15, 533-543. [CrossRef] [PubMed]

56. Paco, A.; de Bessa Garcia, S.A.; Freitas, R. Methylation in HOX clusters and its applications in cancer therapy. Cells 2020, 9 , 1613. [CrossRef]

57. Kim, Y.J.; Gallien, S.; El-Khoury, V.; Goswami, P.; Sertamo, K.; Schlesser, M.; Berchem, G.; Domon, B. Quantification of SAA1 and SAA2 in lung cancer plasma using the isotype-specific PRM assays. Proteomics 2015, 15, 3116-3125. [CrossRef]

58. Ashraf, W.; Ibrahim, A.; Alhosin, M.; Zaayter, L.; Ouararhni, K.; Papin, C.; Ahmad, T.; Hamiche, A.; Mely, Y.; Bronner, C.; et al. The epigenetic integrator UHRF1: On the road to become a universal biomarker for cancer. Oncotarget 2017, 8, 51946-51962. [CrossRef]

59. Alliance of Genome Resources Consortium. The alliance of genome resources: Building a modern data ecosystem for model organism databases. Genetics 2019, 213, 1189-1196. [CrossRef]

60. Panosyan, E.H.; Lin, H.J.; Koster, J.; Lasky, J.L., III. In search of druggable targets for GBM amino acid metabolism. BMC Cancer 2017, 17, 162. [CrossRef] 
61. Zhou, W.; Wahl, D.R. Metabolic abnormalities in glioblastoma and metabolic strategies to overcome treatment resistance. Cancers 2019, 11, 1231. [CrossRef]

62. Engqvist, H.; Parris, T.Z.; Kovacs, A.; Nemes, S.; Werner Ronnerman, E.; De Lara, S.; Biermann, J.; Sundfeldt, K.; Karlsson, P.; Helou, K. Immunohistochemical validation of COL3A1, GPR158 and PITHD1 as prognostic biomarkers in early-stage ovarian carcinomas. BMC Cancer 2019, 19, 928. [CrossRef]

63. Xiao, W.; Chen, K.; Liang, H.G.; Zhang, X.P. Identification of KIF20A as a tumor biomarker and forwarder of clear cell renal cell carcinoma. Chin. Med. J. Engl. 2021. [CrossRef] [PubMed]

64. Joseph, C.; Al-Izzi, S.; Alsaleem, M.; Kurozumi, S.; Toss, M.S.; Arshad, M.; Goh, F.Q.; Alshankyty, I.M.; Aleskandarany, M.A.; Ali, S.; et al. Retinoid X receptor gamma (RXRG) is an independent prognostic biomarker in ER-positive invasive breast cancer. Br. J. Cancer 2019, 121, 776-785. [CrossRef] [PubMed]

65. Pachenari, M.; Seyedpour, S.M.; Janmaleki, M.; Babazadeh Shayan, S.; Taranejoo, S.; Hosseinkhani, H. Mechanical properties of cancer cytoskeleton depend on actin filaments to microtubules content: Investigating different grades of colon cancer cell lines. $J$. Biomech. 2014, 47, 373-379. [CrossRef]

66. Reiss-Zimmermann, M.; Streitberger, K.J.; Sack, I.; Braun, J.; Arlt, F.; Fritzsch, D.; Hoffmann, K.T. High resolution imaging of viscoelastic properties of intracranial tumours by multi-frequency magnetic resonance elastography. Clin. Neuroradiol. 2015, 25, 371-378. [CrossRef] [PubMed]

67. Alibert, C.; Goud, B.; Manneville, J.B. Are cancer cells really softer than normal cells? Biol. Cell. 2017, 109, 167-189. [CrossRef]

68. Ke, X.; Shen, L. Molecular targeted therapy of cancer: The progress and future prospect. Front. Lab. Med. 2017, 1, 69-75. [CrossRef]

69. Boroughs, L.K.; DeBerardinis, R.J. Metabolic pathways promoting cancer cell survival and growth. Nat. Cell Biol. 2015, 17, 351-359. [CrossRef]

70. Masters, C. On the role of the cytoskeleton in metabolic compartmentation. Role Cell Physiol. 1995, 2, 1-30.

71. Marelli-Berg, F.M.; Jangani, M. Metabolic regulation of leukocyte motility and migration. J. Leukoc. Biol. 2018, 104, 285-293. [CrossRef]

72. Zhu, Z.; Leung, G.K.K. More than a metabolic enzyme: MTHFD2 as a novel target for anticancer therapy? Front. Oncol. 2020, 10, 658. [CrossRef] [PubMed]

73. Liu, X.; Peng, J.; Zhou, Y.; Xie, B.; Wang, J. Silencing RRM2 inhibits multiple myeloma by targeting the Wnt/betacatenin signaling pathway. Mol. Med. Rep. 2019, 20, 2159-2166. [PubMed]

74. Kuo, P.H.; Doudeva, L.G.; Wang, Y.T.; Shen, C.K.; Yuan, H.S. Structural insights into TDP-43 in nucleic-acid binding and domain interactions. Nucleic. Acids Res. 2009, 37, 1799-1808. [CrossRef] [PubMed]

75. Zou, Y.; Zhou, J.; Xu, B.; Li, W.; Wang, Z. Ribonucleotide reductase subunit M2 as a novel target for clear-cell renal cell carcinoma. Onco. Targets Ther. 2019, 12, 3267-3275. [CrossRef]

76. Shao, J.; Liu, X.; Zhu, L.; Yen, Y. Targeting ribonucleotide reductase for cancer therapy. Expert Opin. Ther. Targets 2013, 17, 1423-1437. [CrossRef]

77. Fatkhutdinov, N.; Sproesser, K.; Krepler, C.; Liu, Q.; Brafford, P.A.; Herlyn, M.; Aird, K.M.; Zhang, R. Targeting RRM2 and mutant BRAF is a novel combinatorial strategy for melanoma. Mol. Cancer Res. 2016, 14, 767-775. [CrossRef]

78. Aye, Y.; Long, M.J.; Stubbe, J. Mechanistic studies of semicarbazone triapine targeting human ribonucleotide reductase in vitro and in mammalian cells: Tyrosyl radical quenching not involving reactive oxygen species. J. Biol. Chem. 2012, 287, 35768-35778. [CrossRef]

79. Chaston, T.B.; Lovejoy, D.B.; Watts, R.N.; Richardson, D.R. Examination of the antiproliferative activity of iron chelators: Multiple cellular targets and the different mechanism of action of triapine compared with desferrioxamine and the potent pyridoxal isonicotinoyl hydrazone analogue 311. Clin. Cancer Res. 2003, 9, 402-414.

80. Cooperman, B.S.; Gao, Y.; Tan, C.; Kashlan, O.B.; Kaur, J. Peptide inhibitors of mammalian ribonucleotide reductase. Adv. Enzym. Regul. 2005, 45, 112-125. [CrossRef]

81. Shen, H.; He, M.; Lin, R.; Zhan, M.; Xu, S.; Huang, X.; Xu, C.; Chen, W.; Yao, Y.; Mohan, M.; et al. PLEK2 promotes gallbladder cancer invasion and metastasis through EGFR/CCL2 pathway. J. Exp. Clin. Cancer Res. 2019, 38, 247. [CrossRef]

82. Han, X.; Mei, Y.; Schiltz, G.E.; Mishra, R.K.; Jain, A.D.; Ji, P. Abstract 1287: Targeting pleckstrin-2 for the JAK2-STAT and PI3K-Akt pathways in cancer therapy. Exp. Mol. Ther. 2019, 1287. [CrossRef]

83. Zhao, B.; Mei, Y.; Cao, L.; Zhang, J.; Sumagin, R.; Yang, J.; Gao, J.; Schipma, M.J.; Wang, Y.; Thorsheim, C.; et al. Loss of pleckstrin-2 reverts lethality and vascular occlusions in JAK2V617F-positive myeloproliferative neoplasms. J. Clin. Invest. 2018, 128, 125-140. [CrossRef] [PubMed]

84. Hamaguchi, N.; Ihara, S.; Ohdaira, T.; Nagano, H.; Iwamatsu, A.; Tachikawa, H.; Fukui, Y. Pleckstrin-2 selectively interacts with phosphatidylinositol 3-kinase lipid products and regulates actin organization and cell spreading. Biochem. Biophys. Res. Commun. 2007, 361, 270-275. [CrossRef] [PubMed]

85. Zhang, X.; Li, M.; Xu, Y.; Ren, J.; Zeng, A.P. Quantitative study of H protein lipoylation of the glycine cleavage system and a strategy to increase its activity by co-expression of LplA. J. Biol. Eng. 2019, 13, 32. [CrossRef] [PubMed]

86. Kim, D.; Fiske, B.P.; Birsoy, K.; Freinkman, E.; Kami, K.; Possemato, R.L.; Chudnovsky, Y.; Pacold, M.E.; Chen, W.W.; Cantor, J.R.; et al. SHMT2 drives glioma cell survival in ischaemia but imposes a dependence on glycine clearance. Nature 2015, 520, 363-367. [CrossRef] 
87. Kikuchi, G.; Motokawa, Y.; Yoshida, T.; Hiraga, K. Glycine cleavage system: Reaction mechanism, physiological significance, and hyperglycinemia. Proc. Jpn. Acad. Ser. B Phys. Biol. Sci. 2008, 84, 246-263. [CrossRef]

88. Zhang, W.C.; Shyh-Chang, N.; Yang, H.; Rai, A.; Umashankar, S.; Ma, S.; Soh, B.S.; Sun, L.L.; Tai, B.C.; Nga, M.E.; et al. Glycine decarboxylase activity drives non-small cell lung cancer tumor-initiating cells and tumorigenesis. Cell 2012, 148, $259-272$. [CrossRef]

89. Brown, M.J.; Russo, B.C.; O'Dee, D.M.; Schmitt, D.M.; Nau, G.J. The contribution of the glycine cleavage system to the pathogenesis of Francisella tularensis. Microbes. Infect. 2014, 16, 300-309. [CrossRef] [PubMed]

90. Kure, S.; Kojima, K.; Kudo, T.; Kanno, K.; Aoki, Y.; Suzuki, Y.; Shinka, T.; Sakata, Y.; Narisawa, K.; Matsubara, Y. Chromosomal localization, structure, single-nucleotide polymorphisms, and expression of the human H-protein gene of the glycine cleavage system (GCSH), a candidate gene for nonketotic hyperglycinemia. J. Hum. Genet. 2001, 46, 378-384. [CrossRef]

91. Zhuang, H.; Li, Q.; Zhang, X.; Ma, X.; Wang, Z.; Liu, Y.; Yi, X.; Chen, R.; Han, F.; Zhang, N.; et al. Downregulation of glycine decarboxylase enhanced cofilin-mediated migration in hepatocellular carcinoma cells. Free Radic. Biol. Med. 2018, 120, 1-12. [CrossRef] [PubMed]

92. Amelio, I.; Cutruzzola, F.; Antonov, A.; Agostini, M.; Melino, G. Serine and glycine metabolism in cancer. Trends Biochem. Sci. 2014, 39, 191-198. [CrossRef] [PubMed]

93. Jain, M.; Nilsson, R.; Sharma, S.; Madhusudhan, N.; Kitami, T.; Souza, A.L.; Kafri, R.; Kirschner, M.W.; Clish, C.B.; Mootha, V.K. Metabolite profiling identifies a key role for glycine in rapid cancer cell proliferation. Science 2012, 336, 1040-1044. [CrossRef]

94. Rose, M.L.; Cattley, R.C.; Dunn, C.; Wong, V.; Li, X.; Thurman, R.G. Dietary glycine prevents the development of liver tumors caused by the peroxisome proliferator WY-14,643. Carcinogenesis 1999, 20, 2075-2081. [CrossRef] [PubMed]

95. Rose, M.L.; Madren, J.; Bunzendahl, H.; Thurman, R.G. Dietary glycine inhibits the growth of B16 melanoma tumors in mice. Carcinogenesis 1999, 20, 793-798. [CrossRef] [PubMed]

96. Meiser, J.; Vazquez, A. Give it or take it: The flux of one-carbon in cancer cells. FEBS J. 2016, 283, 3695-3704. [CrossRef]

97. Labuschagne, C.F.; van den Broek, N.J.; Mackay, G.M.; Vousden, K.H.; Maddocks, O.D. Serine, but not glycine, supports one-carbon metabolism and proliferation of cancer cells. Cell Rep. 2014, 7, 1248-1258. [CrossRef]

98. Engel, A.L.; Lorenz, N.I.; Klann, K.; Munch, C.; Depner, C.; Steinbach, J.P.; Ronellenfitsch, M.W.; Luger, A.L. Serine-dependent redox homeostasis regulates glioblastoma cell survival. Br. J. Cancer 2020, 122, 1391-1398. [CrossRef]

99. Wei, L.; Jin, Z.; Yang, S.; Xu, Y.; Zhu, Y.; Ji, Y. TCGA-assembler 2: Software pipeline for retrieval and processing of TCGA/CPTAC data. Bioinformatics 2018, 34, 1615-1617. [CrossRef]

100. Ogluszka, M.; Orzechowska, M.; Jedroszka, D.; Witas, P.; Bednarek, A.K. Evaluate cutpoints: Adaptable continuous data distribution system for determining survival in Kaplan-Meier estimator. Comput. Methods Programs Biomed. 2019, 177, 133-139. [CrossRef]

101. Trapnell, C.; Cacchiarelli, D.; Grimsby, J.; Pokharel, P.; Li, S.; Morse, M.; Lennon, N.J.; Livak, K.J.; Mikkelsen, T.S.; Rinn, J.L. The dynamics and regulators of cell fate decisions are revealed by pseudotemporal ordering of single cells. Nat. Biotechnol. 2014, 32, 381-386. [CrossRef]

102. Duan, K.B.; Rajapakse, J.C.; Wang, H.; Azuaje, F. Multiple SVM-RFE for gene selection in cancer classification with expression data. IEEE Trans. Nanobiosci. 2005, 4, 228-234. [CrossRef] [PubMed]

103. Guyon, I.; Weston, J.; Barnhill, S.; Vapnik, V. Gene selection for cancer classification using support vector machines. Mach. Learn. 2002, 46, 389-422. [CrossRef]

104. Ceccarelli, M.; Barthel, F.P.; Malta, T.M.; Sabedot, T.S.; Salama, S.R.; Murray, B.A.; Morozova, O.; Newton, Y.; Radenbaugh, A.; Pagnotta, S.M.; et al. Molecular profiling reveals biologically discrete subsets and pathways of progression in diffuse glioma. Cell 2016, 164, 550-563. [CrossRef] [PubMed]

105. Wu, Q.; Yao, J. BMP4, a new prognostic factor for glioma. World J. Surg. Oncol. 2013, 11, 264. [CrossRef] [PubMed]

106. Zhao, X.; Sun, Q.; Dou, C.; Chen, Q.; Liu, B. BMP4 inhibits glioblastoma invasion by promoting E-cadherin and claudin expression. Front. Biosci. 2019, 24, 1060-1070.

107. Theriault, B.L.; Shepherd, T.G.; Mujoomdar, M.L.; Nachtigal, M.W. BMP4 induces EMT and Rho GTPase activation in human ovarian cancer cells. Carcinogenesis 2007, 28, 1153-1162. [CrossRef]

108. Teh, D.B.L.; Prasad, A.; Jiang, W.; Ariffin, M.Z.; Khanna, S.; Belorkar, A.; Wong, L.; Liu, X.; All, A.H. Transcriptome analysis reveals neuroprotective aspects of human reactive astrocytes induced by interleukin 1beta. Sci. Rep. 2017, 7, 13988. [CrossRef]

109. Tian, M.; Chen, L.; Ma, L.; Wang, D.; Shao, B.; Wu, J.; Wu, H.; Jin, Y. Expression and prognostic significance of CCL11/CCR3 in glioblastoma. Oncotarget 2016, 7, 32617-32627. [CrossRef]

110. Kindstedt, E.; Holm, C.K.; Sulniute, R.; Martinez-Carrasco, I.; Lundmark, R.; Lundberg, P. CCL11, a novel mediator of inflammatory bone resorption. Sci. Rep. 2017, 7, 5334. [CrossRef]

111. Guan, X.; Zhang, C.; Zhao, J.; Sun, G.; Song, Q.; Jia, W. CMTM6 overexpression is associated with molecular and clinical characteristics of malignancy and predicts poor prognosis in gliomas. EBioMedicine 2018, 35, 233-243. [CrossRef]

112. Gao, Y.F.; Mao, X.Y.; Zhu, T.; Mao, C.X.; Liu, Z.X.; Wang, Z.B.; Li, L.; Li, X.; Yin, J.Y.; Zhang, W.; et al. COL3A1 and SNAP91: Novel glioblastoma markers with diagnosticand prognostic value. Oncotarget 2016, 7, 70494-70503. [CrossRef]

113. Gao, Y.F.; Zhu, T.; Chen, J.; Liu, L.; Ouyang, R. Knockdown of collagen alpha-1(III) inhibits glioma cell proliferation and migration and is regulated by miR128-3p. Oncol. Lett. 2018, 16, 1917-1923. 
114. Sun, Y.; Ye, D.; Li, Y.; Chen, E.; Hao, R.; Cai, Y.; Wang, Q.; Wang, O.; Zhang, X. CUX2 functions as an oncogene in papillary thyroid cancer. Onco. Targets Ther. 2019, 12, 217-224. [CrossRef]

115. Cubelos, B.; Sebastian-Serrano, A.; Beccari, L.; Calcagnotto, M.E.; Cisneros, E.; Kim, S.; Dopazo, A.; Alvarez-Dolado, M.; Redondo, J.M.; Bovolenta, P.; et al. Cux1 and Cux2 regulate dendritic branching, spine morphology, and synapses of the upper layer neurons of the cortex. Neuron 2010, 66, 523-535. [CrossRef]

116. Mills, B.N.; Albert, G.P.; Halterman, M.W. Expression profiling of the MAP kinase phosphatase family reveals a role for DUSP1 in the glioblastoma stem cell niche. Cancer Microenviron. 2017, 10, 57-68. [CrossRef] [PubMed]

117. Tischer, T.; Schuh, M. The phosphatase dusp7 drives meiotic resumption and chromosome alignment in mouse oocytes. Cell Rep. 2016, 17, 1426-1437. [CrossRef] [PubMed]

118. Spichal, M.; Fabre, E. The Emerging role of the cytoskeleton in chromosome dynamics. Front. Genet. 2017, 8, 60. [CrossRef]

119. Zou, H.; Li, C.; Wanggou, S.; Li, X. Survival risk prediction models of gliomas based on IDH and 1p/19q. J. Cancer 2020, 11, 4297-4307. [CrossRef]

120. Li, F.Q.; Chen, X.; Fisher, C.; Siller, S.S.; Zelikman, K.; Kuriyama, R.; Takemaru, K.I. BAR domain-containing FAM92 proteins interact with chibby1 to facilitate ciliogenesis. Mol. Cell Biol. 2016, 36, 2668-2680. [CrossRef] [PubMed]

121. Fiscon, G.; Conte, F.; Licursi, V.; Nasi, S.; Paci, P. Computational identification of specific genes for glioblastoma stem-like cells identity. Sci. Rep. 2018, 8, 7769. [CrossRef]

122. Tong, L.; Yi, L.; Liu, P.; Abeysekera, I.R.; Hai, L.; Li, T.; Tao, Z.; Ma, H.; Xie, Y.; Huang, Y.; et al. Tumour cell dormancy as a contributor to the reduced survival of GBM patients who received standard therapy. Oncol. Rep. 2018, 40, 463-471. [CrossRef]

123. Tuncbag, N.; Milani, P.; Pokorny, J.L.; Johnson, H.; Sio, T.T.; Dalin, S.; Iyekegbe, D.O.; White, F.M.; Sarkaria, J.N.; Fraenkel, E. Network modeling identifies patient-specific pathways in glioblastoma. Sci. Rep. 2016, 6, 28668. [CrossRef]

124. Pollak, J.; Rai, K.G.; Funk, C.C.; Arora, S.; Lee, E.; Zhu, J.; Price, N.D.; Paddison, P.J.; Ramirez, J.M.; Rostomily, R.C. Ion channel expression patterns in glioblastoma stem cells with functional and therapeutic implications for malignancy. PLoS ONE 2017, 12, e0172884. [CrossRef]

125. Hu, C.; Chen, W.; Myers, S.J.; Yuan, H.; Traynelis, S.F. Human GRIN2B variants in neurodevelopmental disorders. J. Pharmacol. Sci. 2016, 132, 115-121. [CrossRef]

126. Zhao, Y.; Zhang, X.; Yao, J.; Jin, Z.; Liu, C. Expression patterns and the prognostic value of the EMILIN/Multimerin family members in low-grade glioma. PeerJ 2020, 8, e8696. [CrossRef] [PubMed]

127. Shi, T.; Guo, D.; Xu, H.; Su, G.; Chen, J.; Zhao, Z.; Shi, J.; Wedemeyer, M.; Attenello, F.; Zhang, L.; et al. HOTAIRM1, an enhancer lncRNA, promotes glioma proliferation by regulating long-range chromatin interactions within HOXA cluster genes. Mol. Biol. Rep. 2020, 47, 2723-2733. [CrossRef]

128. Zhang, X.; Emerald, B.S.; Mukhina, S.; Mohankumar, K.M.; Kraemer, A.; Yap, A.S.; Gluckman, P.D.; Lee, K.O.; Lobie, P.E. HOXA1 is required for E-cadherin-dependent anchorage-independent survival of human mammary carcinoma cells. J. Biol. Chem. 2006, 281, 6471-6481. [CrossRef]

129. Kim, J.W.; Kim, J.Y.; Kim, J.E.; Kim, S.K.; Chung, H.T.; Park, C.K. HOXA10 is associated with temozolomide resistance through regulation of the homologous recombinant DNA repair pathway in glioblastoma cell lines. Genes Cancer 2014, 5, 165-174. [CrossRef]

130. Dong, C.Y.; Cui, J.; Li, D.H.; Li, Q.; Hong, X.Y. HOXA10AS: A novel oncogenic long noncoding RNA in glioma. Oncol. Rep. 2018, 40, 2573-2583.

131. Kallen, A.N.; Haines, K.; Taylor, H.S. HOXA10 regulates expression of cytokeratin 15 in endometrial epithelial cytoskeletal remodeling. Reprod. Sci. 2014, 21, 892-897. [CrossRef] [PubMed]

132. Groth-Pedersen, L.; Aits, S.; Corcelle-Termeau, E.; Petersen, N.H.; Nylandsted, J.; Jaattela, M. Identification of cytoskeletonassociated proteins essential for lysosomal stability and survival of human cancer cells. PLoS ONE 2012, 7, e45381. [CrossRef]

133. Smith, N.; Saunders, D.; Jensen, R.L.; Towner, R.A. Association of decreased levels of lipopolysaccharide-binding protein with OKN-007-induced regression of tumor growth in an F98 rat glioma model. J. Neurosurg. 2019, 1-9. [CrossRef] [PubMed]

134. Inoue, A.; Takahashi, H.; Harada, H.; Kohno, S.; Ohue, S.; Kobayashi, K.; Yano, H.; Tanaka, J.; Ohnishi, T. Cancer stem-like cells of glioblastoma characteristically express MMP-13 and display highly invasive activity. Int. J. Oncol. 2010, 37, $1121-1131$.

135. Wang, J.; Li, Y.; Wang, J.; Li, C.; Yu, K.; Wang, Q. Increased expression of matrix metalloproteinase-13 in glioma is associated with poor overall survival of patients. Med. Oncol. 2012, 29, 2432-2437. [CrossRef]

136. Lehtinen, L.; Ketola, K.; Makela, R.; Mpindi, J.P.; Viitala, M.; Kallioniemi, O.; Iljin, K. High-throughput RNAi screening for novel modulators of vimentin expression identifies MTHFD2 as a regulator of breast cancer cell migration and invasion. Oncotarget 2013, 4, 48-63. [CrossRef]

137. Guerrero, P.A.; Yin, W.; Camacho, L.; Marchetti, D. Oncogenic role of Merlin/NF2 in glioblastoma. Oncogene 2015, 34, 2621-2630. [CrossRef]

138. Cole, B.K.; Curto, M.; Chan, A.W.; McClatchey, A.I. Localization to the cortical cytoskeleton is necessary for Nf2/merlin-dependent epidermal growth factor receptor silencing. Mol. Cell Biol. 2008, 28, 1274-1284. [CrossRef]

139. Bashour, A.M.; Meng, J.J.; Ip, W.; MacCollin, M.; Ratner, N. The neurofibromatosis type 2 gene product, merlin, reverses the F-actin cytoskeletal defects in primary human Schwannoma cells. Mol. Cell Biol. 2002, 22, 1150-1157. [CrossRef]

140. Mhyre, A.J.; Turnbaugh, S.; Morris, S.M.; Xin, H.; Paddison, P.J.; Ferrer, M.; Olson, J.M. Abstract 3200: Targeting PHF5A for the treatment of glioblastoma and other Myc-driven cancers. Exp. Mol. Ther. 2017, 3200. [CrossRef] 
141. Chen, X.; Pan, C.; Xu, C.; Sun, Y.; Geng, Y.; Kong, L.; Xiao, X.; Zhao, Z.; Zhou, W.; Huang, L.; et al. Identification of survivalassociated key genes and long noncoding RNAs in glioblastoma multiforme by weighted gene coexpression network analysis. Int. J. Mol. Med. 2019, 43, 1709-1722.

142. Zhao, B.; Keerthivasan, G.; Mei, Y.; Yang, J.; McElherne, J.; Wong, P.; Doench, J.G.; Feng, G.; Root, D.E.; Ji, P. Targeted shRNA screening identified critical roles of pleckstrin-2 in erythropoiesis. Haematologica 2014, 99, 1157-1167. [CrossRef] [PubMed]

143. Xiang, Y.; Zhang, C.Q.; Huang, K. Predicting glioblastoma prognosis networks using weighted gene co-expression network analysis on TCGA data. BMC Bioinform. 2012, 13 (Suppl. 2), S12. [CrossRef] [PubMed]

144. Feldheim, J.; Kessler, A.F.; Schmitt, D.; Salvador, E.; Monoranu, C.M.; Feldheim, J.J.; Ernestus, R.I.; Löhr, M.; Hagemann, C. Ribosomal protein S27/Metallopanstimulin-1 (RPS27) in Glioma-A new disease biomarker? Cancers 2020, 12, 1085. [CrossRef]

145. Rasmussen, R.D.; Gajjar, M.K.; Tuckova, L.; Jensen, K.E.; Maya-Mendoza, A.; Holst, C.B.; Møllgaard, K.; Rasmussen, J.S.; Brennum, J.; Bartek, J., Jr.; et al. BRCA1-regulated RRM2 expression protects glioblastoma cells from endogenous replication stress and promotes tumorigenicity. Nat. Commun. 2016, 7, 13398. [CrossRef]

146. Kitab, B.; Satoh, M.; Ohmori, Y.; Munakata, T.; Sudoh, M.; Kohara, M.; Tsukiyama-Kohara, K. Ribonucleotide reductase M2 promotes RNA replication of hepatitis C virus by protecting NS5B protein from hPLIC1-dependent proteasomal degradation. J. Biol. Chem. 2019, 294, 5759-5773. [CrossRef]

147. Shah, P.P.; Lockwood, W.W.; Saurabh, K.; Kurlawala, Z.; Shannon, S.P.; Waigel, S.; Zacharias, W.; Beverly, L.J. Ubiquilin1 represses migration and epithelial-to-mesenchymal transition of human non-small cell lung cancer cells. Oncogene 2015, 34, 1709-1717. [CrossRef]

148. Papi, A.; Tatenhorst, L.; Terwel, D.; Hermes, M.; Kummer, M.P.; Orlandi, M.; Heneka, M.T. PPARgamma and RXRgamma ligands act synergistically as potent antineoplastic agents in vitro and in vivo glioma models. J. Neurochem. 2009, 109, 1779-1790. [CrossRef]

149. Ana, C.; Gilberto, K.; Raquel, H.; Luziane, B.; Franciele, K. Effect of SAA1, SAA2 and SAA4 knockdown on proliferation and invasion of glioblastomas multiformes cells. Front. Immunol. 2013, 4. [CrossRef]

150. Yu, F.; Li, G.; Gao, J.; Sun, Y.; Liu, P.; Gao, H.; Li, P.; Lei, T.; Chen, Y.; Cheng, Y.; et al. SPOCK1 is upregulated in recurrent glioblastoma and contributes to metastasis and Temozolomide resistance. Cell Prolif. 2016, 49, 195-206. [CrossRef] [PubMed]

151. Yang, J.; Yang, Q.; Yu, J.; Li, X.; Yu, S.; Zhang, X. SPOCK1 promotes the proliferation, migration and invasion of glioma cells through PI3K/AKT and Wnt/beta-catenin signaling pathways. Oncol. Rep. 2016, 35, 3566-3576. [CrossRef]

152. Chen, Q.; Yao, Y.T.; Xu, H.; Chen, Y.B.; Gu, M.; Cai, Z.K.; Wang, Z. SPOCK1 promotes tumor growth and metastasis in human prostate cancer. Drug Des. Devel. Ther. 2016, 10, 2311-2321. [PubMed]

153. Ribeiro, J.R.; Lovasco, L.A.; Vanderhyden, B.C.; Freiman, R.N. Targeting TBP-associated factors in ovarian cancer. Front. Oncol. 2014, 4, 45. [CrossRef] [PubMed]

154. Collet, B.; Guitton, N.; Saikali, S.; Avril, T.; Pineau, C.; Hamlat, A.; Mosser, J.; Quillien, V. Differential analysis of glioblastoma multiforme proteome by a 2D-DIGE approach. Proteome Sci. 2011, 9, 16. [CrossRef]

155. Sousa, M.M.; Yan, S.D.; Stern, D.; Saraiva, M.J. Interaction of the receptor for advanced glycation end products (RAGE) with transthyretin triggers nuclear transcription factor kB (NF-kB) activation. Lab. Invest. 2000, 80, 1101-1110. [CrossRef]

156. Xiong, F.; Leonov, S.; Howard, A.C.; Xiong, S.; Zhang, B.; Mei, L.; McNeil, P.; Simon, S.; Xiong, W.C. Receptor for advanced glycation end products (RAGE) prevents endothelial cell membrane resealing and regulates F-actin remodeling in a beta-catenindependent manner. J. Biol. Chem. 2011, 286, 35061-35070. [CrossRef]

157. Boukhari, A.; Alhosin, M.; Bronner, C.; Sagini, K.; Truchot, C.; Sick, E.; Schini-Kerth, V.B.; André, P.; Mély, Y.; Mousli, M.; et al. CD47 activation-induced UHRF1 over-expression is associated with silencing of tumor suppressor gene p16INK4A in glioblastoma cells. Anticancer Res. 2015, 35, 149-157.

158. Matsushita, R.; Yoshino, H.; Enokida, H.; Goto, Y.; Miyamoto, K.; Yonemori, M.; Inoguchi, S.; Nakagawa, M.; Seki, N. Regulation of UHRF1 by dual-strand tumor-suppressor microRNA-145 (miR-145-5p and miR-145-3p): Inhibition of bladder cancer cell aggressiveness. Oncotarget 2016, 7, 28460-28487. [CrossRef]

159. Kijima, N.; Hosen, N.; Kagawa, N.; Hashimoto, N.; Kinoshita, M.; Oji, Y.; Sugiyama, H.; Yoshimine, T. Wilms' tumor 1 is involved in tumorigenicity of glioblastoma by regulating cell proliferation and apoptosis. Anticancer Res. 2014, 34, 61-67.

160. Dudnakova, T.; Spraggon, L.; Slight, J.; Hastie, N. Actin: A novel interaction partner of WT1 influencing its cell dynamic properties. Oncogene 2010, 29, 1085-1092. [CrossRef] 